\title{
VISUAL, OLFACTORY, AND VOCAL CUES TO FECUNDITY IN HUMAN FEMALES
}

\section{DISSERTATION}

zur Erlangung des mathematisch-naturwissenschaftlichen Doktorgrades

"Doctor rerum naturalium"

der Georg-August-Universität Göttingen

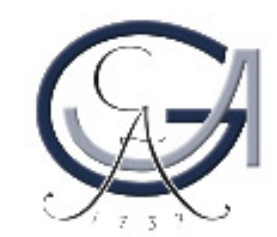

im Grundprogramm

der Georg-August University School of Science (GAUSS)

vorgelegt von

Susanne Röder

aus Herford

Göttingen, 2013 
Betreuungsausschuss

Betreuer und Anleiter: Dr. Bernhard Fink Institut für Psychologie \& Courant Research Center "Evolution of Social Behavior"

Emmy-Noether-Research Group

Universität Göttingen

Betreuer:

Prof. Dr. Peter M. Kappeler

Institut für Zoologie \& Anthropologie

Abteilung Soziobiologie/ Anthropologie

Universität Göttingen

$\underline{\text { Mitglieder der Prüfungskommission }}$

Referent: Dr. Bernhard Fink

Korreferent: Prof. Dr. Peter M. Kappeler

$\underline{\text { Weitere Mitglieder der Prüfungskommission }}$

Prof. Dr. Margarete Boos; Institut für Psychologie; Universität Göttingen

Prof. Dr. Lars Penke; Institut für Psychologie; Universität Göttingen

Prof. Dr. Stefan Schulz-Hardt; Institut für Psychologie; Universität Göttingen

Prof. Dr. Dirk Semmann; Courant Research Center "Evolution of Social Behavior"; Universität Göttingen

Tag der mündlichen Prüfung: 21. November 2013 
This thesis is dedicated to my lovely family. 


\section{CONTENTS}

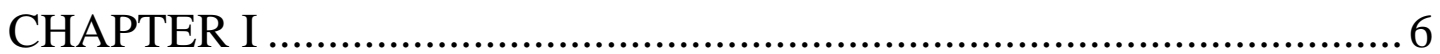

GENERAL INTRODUCTION .................................................................................6

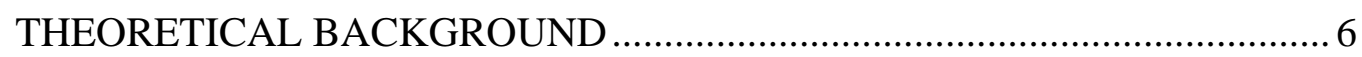

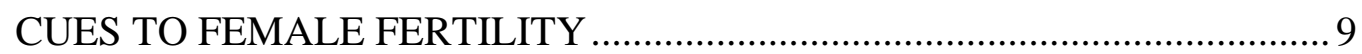

THE FEMALE REPRODUCTIVE LIFE SPAN ............................................. 12

CROSS-MODALITY PERCEPTION OF ATTRACTIVENESS ...................... 14

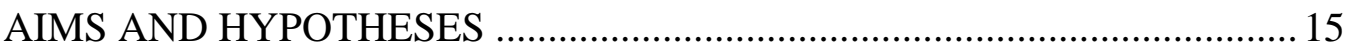

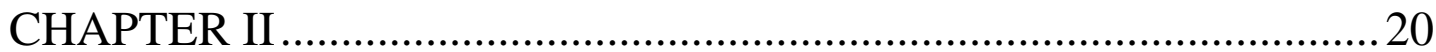

FACIAL, OLFACTORY, AND VOCAL CUES_TO FEMALE REPRODUCTIVE VALUE .............................................................................20

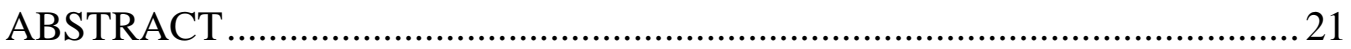

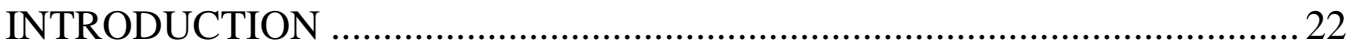

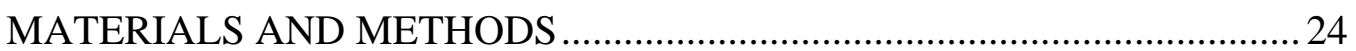

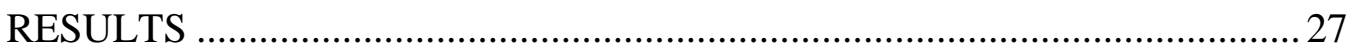

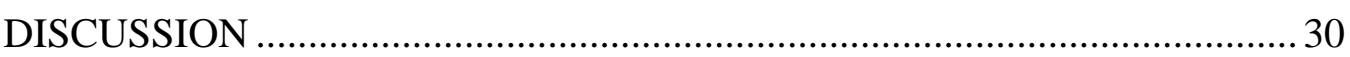

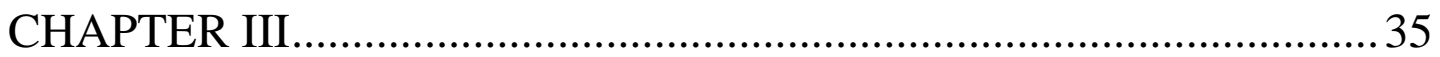

FACIAL VISUALIZATIONS OF WOMEN'S VOICES_SUGGEST A CROSS-MODALITY PREFERENCE_FOR FEMININITY ..............................35

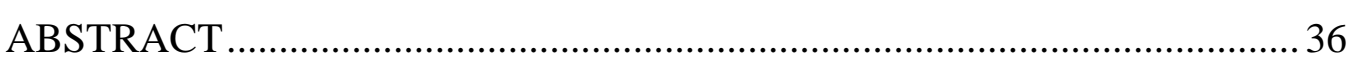

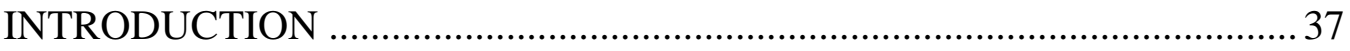

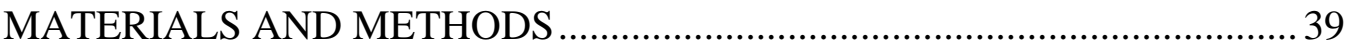

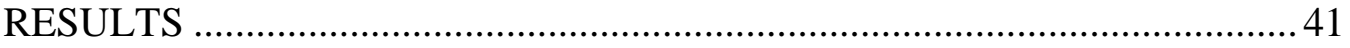

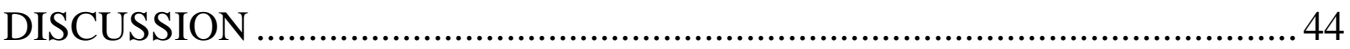

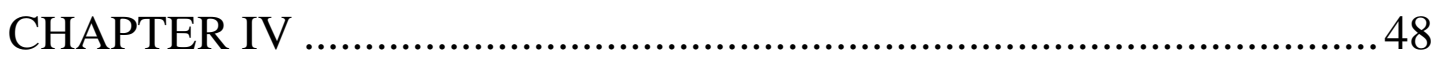

WOMEN'S FACES AND VOICES:_ONE ORNAMENT OF QUALITY?.... 48

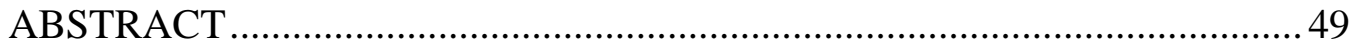

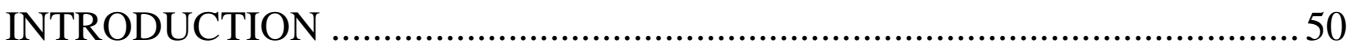

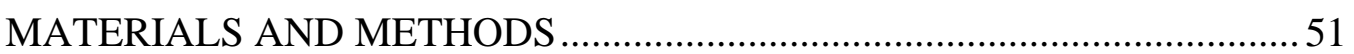

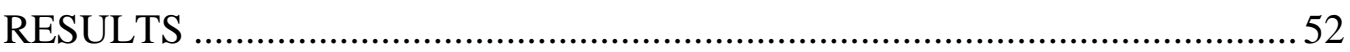

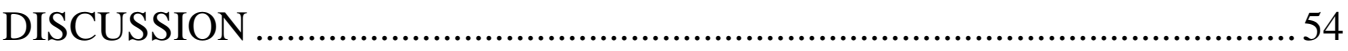




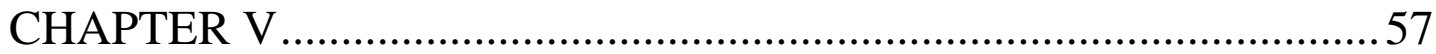

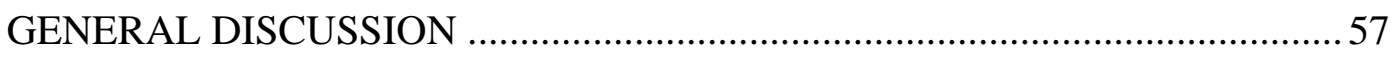

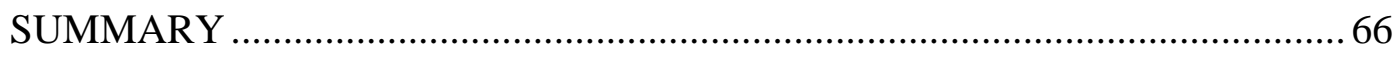

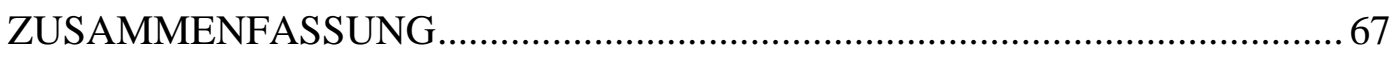

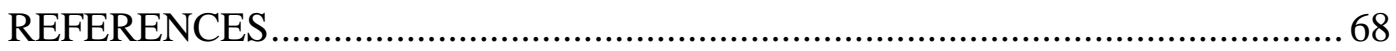

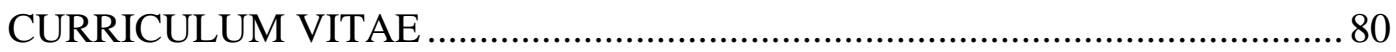

ERKLÄRUNG ÜBER EIGENE LEISTUNG ……………………………....... 84

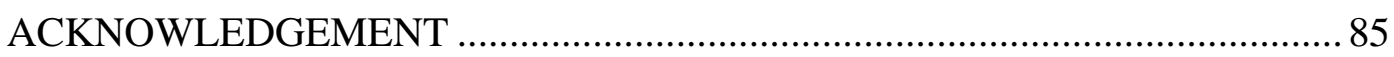




\section{GENERAL INTRODUCTION}

\section{THEORETICAL BACKGROUND}

One of the major interests of evolutionary psychologists is to understand the mechanisms of human mate preferences and selection, probably because it concerns all humans at least once in their lifetime. Research has recognized the variability of human mating mechanisms and strategies in men and women (Buss and Schmitt, 1993; Andersson, 1994; Buss, 1994), and has provided confirmatory studies demonstrating that these mechanisms are firmly rooted in our brain. A key insight is that of the significance of human physical appearance in mate selection and mating decisions (e.g. Buss and Schmitt, 1993; Buss, 1994; Fink and Penton-Voak, 2002; Grammer et al., 2003a; Rhodes, 2006). Evolutionary psychologists have argued that in humans, like in other animals, sexually selected physical characteristics are related to health. Thereby, they suggest that humans have evolved to view certain features as attractive and preferable (Barber, 1995), because mating with healthy individuals has reproductive benefits. In this view, the human obsession with beauty is not different from that of other animals.

An important insight into human mating that has been deduced from parental investment theory (Trivers, 1972), is that differences in mate preferences and mating strategies between men and women exist. This theory proposes that males are competing with other males in order to get access to potential fertile mating partners. This is explained by the biological limit on how many offspring males and females can have in their lifetime. The biological limitation for females is thereby determined by the time of pregnancy, lactation and protection of offspring, whereas for males the limiting factor is the number of fertile women to which they can gain sexual access (Geary, Vigil and Byrd-Craven, 2004).

Numerous studies across different cultures have shown that men have a higher preference for female physical attractiveness than women have for male 
attractiveness. In contrast, women rank male status and resource acquisition higher than men rank female status and resources (Buss and Schmitt, 1993; Buss, 1994; Schmitt et al., 2003). Physical attractiveness in women is thought to signal youth, fertility, and health, whereas male status and resources signal competitive ability, social dominance, and health (Fink and Penton-Voak, 2002; Grammer et al., 2003a; Rhodes, 2006).

To enhance their reproductive success, ancestral men had to choose mates who signalled a high reproductive potential. Therefore, males should have preferred attributes in potential mates, which are associated with fertility and health. However, in human females, ovulation is thought to be concealed or cryptic, and that women do not display clear signals of fertility. Evolutionary theory on sexual behaviour in humans has been built around the hypothesis that women have lost a distinct phase of fertility within their reproductive cycle (Jolly, 1972; Alexander and Noonan, 1979; Alexander, 1990), as it has been reported for our closest relatives. More precisely, concealed ovulation means that women, in contrast to most other mammalian (placental) females, lack external cues of ovulation. When, for example, the female chimpanzee is capable of conceiving, she enters a phase called "oestrus", or "heat" which is the time around ovulation when the female shows maximum sexual receptivity. The oestrus cycle comprises recurring physiological changes that are induced by reproductive hormones (e.g., oestrogen) in most mammalian females. This distinct phase of fertility is typically associated with enhanced proceptivity and receptivity to males, and is frequently linked to certain sensory cues like changes in vaginal aliphatic acids that apparently function as a stimulating "pheromone" in rhesus monkeys, or large sexual swellings in chimpanzees. Women do not exhibit an evident period of heat, as they display sexual activity during their entire menstrual cycle (see Thornhill and Gangestad, 2008). The hypotheses trying to explain this phenomenon state that concealed ovulation in human females evolved, because it (i) promotes paternity certainty and paternal care (Alexander \& Noonan, 1979), (ii) promotes paternity confusion by reducing the risk of infanticide (Hrdy, 1981), and (iii) reduces the risk that human females will resort to contraception in order to avoid the anticipated pain of childbirth (Burley, 1979). 
Assuming that the longstanding theory of concealed ovulation is true, the evolution from advertised oestrus to concealed ovulation in humans posed a significant adaptive problem for our ancestral males, who needed to develop mechanisms in order to discern potential fertile mates from non-fertile mates. Hence, concealed ovulation shifted the problem from detecting woman's ovulation (fertile phase) to determining a women's reproductive potential (see Buss, 2008, Thornhill and Gangestad, 2008). Thus, research on human mating behaviour assumes that ancestral men could have evolved preferences for characteristics that correlate with current fertility, but also with reproductive potential, to maximize their reproductive success. In fact, recent evidence from the evolutionary study of human sexual behaviour suggest that there are certain visual, olfactory and vocal cues that serve as indirect signals of a women's fertility (see Thornhill and Gangestad, 2008) because they show hormone-associated changes during the menstrual cycle. Literature on evolutionary research documents changes in women's motivations, desires, and behaviours across the menstrual cycle (for review see Gangestad and Thornhill 2008, Thornhill and Gangestad, 2008; Haselton and Gildersleeve, 2011), indicating that women possess "a modified phase of female sexuality", occurring near ovulation, and which is different from other, non-fertile phases of the menstrual cycle (Gildersleeve et al., in press).

Woman's fertility changes within a standard 28-day cycle and they are fertile only for a brief period of their menstrual cycle. Fertility increases with rising oestrogen concentration in the second week of the menstrual cycle and decreases with the decline of oestrogen concentration after ovulation (Nelson, 2000; Wilcox etal., 1995). The days of high fertility ("fertile window") are approximately defined as six days, ending with the day of ovulation, fourteen days after onset of menses. The days before and the days after the fertile window are associated with a very low conception risk, and therefore defined as non-fertile cycle days (e.g. Wilcox et al., 1995, Dunson et al., 1999).

Research has found that men's perception of women's physical attractiveness varies across the menstrual cycle (Miller et al., 2007; Roberts et al., 2004; Pipitone and Gallup, 2008; Havlicek et al., 2006). Contrary to the concealed ovulation hypothesis, these studies suggest that subtle sensory cues to women's fertility exist 
and are perceived by men. The conventional methodology to test this male sensitivity to cues of women's fertility predominantly investigates the variation of visual, olfactory, and vocal signals across women's menstrual cycle (see for review Thornhill and Gangestad, 2008).

\section{CUES TO FEMALE FERTILITY}

\section{Face and body attractiveness}

Roberts et al. (2004) collected facial photographs of 48 women at high- and low fertile days and presented the facial images to male and female participants, who were asked to choose the face they found more attractive. It has found that men judged photographs of women's faces taken at days of high fertility as more attractive than those taken at days of low fertility. The authors argued that these perceptual differences might be caused by changes of (facial) soft tissue across the menstrual cycle. Manning et al. (1996) and Scutt and Manning (1996) tested this hypothesis by examining changes in the soft tissue of physical characteristics such as ears, fingers, and breasts. They found that in female participants left-right symmetry in these traits was higher when measured at days of high fertility than at days of low fertility. Given that facial and body symmetry are known to affect physical attractiveness judgements (Grammer and Thornhill, 1994; Grammer et al., 2001), increased symmetry on days of high fertility could signal (reproductive) health (Thornhill and Gangestad, 2008). Additionally, Kirchengast and Gartner (2002) reported morphological changes of women's body weight and waist-to-hip ratio during the menstrual cycle. They found smaller (more feminine) waist-to-hip ratios (WHR) in women when measured at days of high fertility than at days of low fertility. One possible explanation is that these effects are due to the retention of body fluid during the pre- menstrual and menstrual phase.

Additional studies have suggested that facial skin colour becomes lighter around ovulation (van den Berghe and Frost, 1986), possibly because oestrogen suppresses the production of melanin, leading to a more even skin tone. If this is true, then oestrogen may enhance facial attractiveness incidentally via smoothing skin tone, and men may have evolved adaptations to visually discern these differences. 
However, this hypothesis has not yet been proven and needs further empirical investigation. This also applies to preliminary findings of changes in women's body movements throughout the cycle. Provost, Troje and Quinsey (2008) and more recently Fink and colleagues (2012) investigated differences in male perceptions of female body movement at high and low fertile days. Fink and colleagues (2012) collected video clips of women's body movement once on high fertile days and a second time on low fertile days and asked male participants to rate them on attractiveness. They found that body movements of women collected on fertile days were judged to be more attractive than those collected on low fertile days. The authors concluded that men are sensitive to subtle changes in women's body movement, which are also linked to female fertility.

\section{Body odour attractiveness}

Furthermore, it has been found that body odour plays an important role in human sexual behaviour. Poran (1994) found that men perceived the smell of female body odour samples as more attractive, when collected during fertile days, compared to samples collected during non-fertile days. He studied pair-bonded couples with females not using hormonal contraceptives and found that men rated the odour of their mates around ovulation as more desirable than on other days of the menstrual cycle. Two studies by Grammer and colleagues suggested that such effects might be due to the variation in "copulins", volatile fatty acids, in vaginal secretions across a woman's menstrual cycle (Grammer et al., 1997; Grammer et al., 2005). Around ovulation, women produce the greatest amount of "copulins", whereas the production declines during the luteal phase of the menstrual cycle (Preti and Huggins, 1975). More recent studies, which investigated menstrual cycle dependent variation in female body odour perception, used the "worn T-shirt methodology". Singh and Bronstad (2001) reported that the odours of T-shirts worn by women during the follicular and luteal phases differed in perceived pleasantness or sexiness, a result that was been more recently replicated by Havlicek et al. (2006) and Kuukasjärvi et al. (2004). To collect the body odour samples, these authors asked participants to sleep in a T-shirt for three consecutive nights. All participants were provided detailed instructions of behavioural restrictions during the three days of data collection to ensure standardized conditions. However, Thornhill and Gangestad (2008) 
mentioned that the effect of menstrual cycle changes on female body odour seems to be subtle, this is possibly not because of men's reduced ability in detecting such changes of the scent, but because selection has acted on women to reduce the production and/or emission of olfactory cues of her fertility status.

\section{Voice attractiveness}

The human voice has also been found to transmit important biological information. Women have higher pitched voices than men, which seem to be associated with sex steroids, primarily testosterone and oestrogen (Abitbol et al., 1999), as the larynx is sensitive to these hormones (Caruso et al., 2000). With the onset of puberty, hormonal changes affect the morphology of the larynx and shape the mature female voice, which is higher pitched than the mature male voice (Abitbol et al., 1999). In women, this difference in voice pitch is associated with the varied influence of oestrogen from childhood to menopause (Abitbol et al., 1999). Collins and Missing (2003) reported that feminised voices (with raised pitch) were judged as more attractive than masculinised voices (with lowered pitch) (see also Apicella and Feinberg, 2009), a finding that was recently replicated by Saxton et al. (2009). The general conclusion of these studies is that vocal quality, such as voice pitch, conveys information about female mate quality in terms of fertility, just as visual and olfactory cues do. If this were true, then one would also expect menstrual cycle variations in vocal quality, as has been found for faces and body odours. Pipitone and Gallup (2008) investigated this possibility by presenting women's voices, recorded at different times of their menstrual cycle, to a panel of male judges. It was found that men judged the voices of women recorded near ovulation as more attractive than the voices of the same women recorded during their non-fertile days.

In conclusion, literature focussed on changes in women's attractiveness across the menstrual cycle indicates fertility-related variations in women's facial, olfactory and vocal attractiveness, and men's sensitivity to these variations. It has been argued that attractiveness reflects mate 'quality' (in a Darwinian sense), because men are supposed to be particularly sexually attracted by those features (and woman), which signal high reproductive potential. Due to the reported results of the recent literature about menstrual cycle dependent changes in women's facial, olfactory, and vocal attractiveness, researchers propose that women, in fact, possess a distinct phase 
of fertile sexuality that is functionally homologues and similar to oestrus observed in other species (see Tarìn and Gómez-Piquer, 2002). Hence, Thornhill and Gangestad (2008) recommended that the model of concealed ovulation in human females may need to be reconsidered, as recent studies of human sexual behaviour suggests that there are certain visual, olfactory and vocal cues that are linked to women's reproductive potential (see review of Thornhill and Gangestad, 2008; Gangestad and Thornhill, 2008). However, most evidence for the relationship between women's visual, olfactory and vocal attractiveness and reproductive potential is based on studies investigating menstrual cycle related differences in samples of young adult women, which only consider a small age range of a women's reproductive life span. In women more than in men, reproductive potential is a function of age, starting at the age of menarche and ending at the age of menopause.

\section{THE FEMALE REPRODUCTIVE LIFE SPAN}

Women's reproductive potential refers to the number of children a woman of a given age can have in the future. Thus, a 15-year-old woman has a higher reproductive potential than a 25-year-old woman, whereas the latter has a higher fertility, because in the mid-twenties the chance to conceive is highest. Furthermore, women's fecundity (reproductive life span) starts with the menarche (about the age of 15 years) and ends with the menopause (between the ages of 40 to 60; see Morabia and Constanza, 1998; Gordon and Laufer, 2005). Menarche and menopause are therefore the two major occurrences in women's reproductive life. A woman's reproductive period lasts some 25 years, whereas the pre- and post-reproductive life span together last approximately 60 years (Fedigan and Pavelka, 1994). Women's short reproductive life span also constrains men's reproductive ability in that men's potential reproductive success is mainly limited by their access to fertile women. Evolutionary psychologists argue that selection pressures have therefore operated on men's ability to discern women who can reproduce from those who cannot, in order to enhance their own reproductive success. This male ability to assess female fecundity based on certain cues might be particularly significant for women around the age of menarche and menopause, because these mark the beginning and end of a woman's reproductive life span. In contrast to most placental mammals (and some 
primates), human females are sexually receptive throughout their reproductive life span, that is, between the ages of about 15 to 45 years at which maximum fertility typically occurs during the early 20s, and chance to get pregnant is highest. After the age of 30 years, a woman's fertility decreases at a higher rate (see Broekmans et al., 2007). Related to the assumption, that men are sensitive to certain cues in women that signal reproductive capacity, they should be attracted by women, who signal youth and high reproductive potential, which is from the biological point of view, the age of late adolescence (Marshall and Tanner, 1974). Studies have shown that sexually attractive body features such as breast size and the waist-to-hip-ratio (WHR) develop during puberty as a result of hormonal stimulation and are fully developed by late adolescence, when mate choice becomes important. Thus, such features are argued to function as signals indicating women's fertility, and to be markers of women's reproductive potential (Thornhill and Gangestad, 2008). The development of sexually attractive characteristics during sexual maturity as well as fertility, are both affected by varying levels of oestrogen.

Evolutionary theories propose that the males might be attracted to indicators of high levels of oestrogen since they reflect genetic quality. High levels of testosterone and oestrogen suppress the immune system and therefore, prominent attractiveness characteristics should be related to a healthier immune system. According to Følstad and Karter (1992), the expression of secondary sexual characteristics reliably signals health because only healthy individuals can withstand the immunosuppressive development of distinct characteristics (Rhodes et al., 2005). Mating with an attractive individual will result in mating with an individual of high genetic quality. One of the most robust findings on physical attractiveness is that men are particularly attracted to female faces with feminine proportions (Johnston and Franklin, 1993). Typical feminine facial features, like prominent cheekbones as well as pronounced eyes and lips develop under the influence of oestrogen. Law Smith and colleagues (2006) found that feminine looking female faces were perceived to appear more attractive and healthy compared to those, which were perceived as being less feminine. Judged facial attractiveness and healthiness also correlated positively with women's current oestrogen levels. Additionally, studies reported that feminine facial features also change with women's age and their reproductive potential: less feminine faces get longer, eyebrows more prominent and 
lips smaller (Johnston and Franklin, 1993; Jones, 1995; Symons, 1995). In women, facial femininity is therefore discussed as an important feature of attractiveness. In addition to feminine facial features, women's facial skin similarly appears to be improved by oestrogen, because skin morphology is sexually dimorphic between men and women (Fink et al., 2006). In addition, Singh and Young (1995) found that women with a WHR of about 0.7 are judged to be more attractive by men than women with a lower WHR (0.6 or lower) or a higher WHR (0.8 or higher). The WHR has been shown to correlate strongly with general health and fertility as women within the 0.7-range have higher levels of oestrogen. Thus, female body morphology is shaped under the influence of oestrogen. Women's voices are also known to be sexually dimorphic (e. g., voice pitch in women is higher) developing under the influence of oestrogen (Abitbol et al., 1999). Moreover, it is known that voices of older people differ from those of younger people (Ryan, 1972; Zenker, 1964; Sweeting and Baken, 1982; Orlikoff, 1990) with children having higher pitched voices than adults. Voice research has shown that in the context of the agerelated decline in oestrogen levels, voices of younger women receive higher attractiveness ratings than voices of older women (Collins \& Missing, 2003). In that study male participants were asked to judge first the attractiveness of the female voices they heard and then to rate the age of the speaker in years. Those women who were perceived to be younger also had higher pitched voices (fundamental frequencies) compared to those women who were perceived to be older.

\section{CROSS-MODALITY PERCEPTION OF ATTRACTIVENESS}

Research on women's attractiveness has shown that women's attractiveness relates to oestrogen and that this applies to different characteristics in the same way (e.g., faces, body odours and voices). More recent research reported that in women, oestrogen-enhanced facial features increase a women's perceived attractiveness, which was also reported for higher pitched voices in relation to oestrogen levels. These findings support the assumption that female faces, bodies and voices are all influenced by oestrogen, and thus serve as a cue to mate quality. Remarkably, further studies investigating women's attractiveness indicated that attractiveness perceptions are correlated across different modalities. They found that individuals rated as 
attractive for one characteristic were also rated as attractive for other characteristics (Thornhill and Grammer, 1999; Collins and Missing, 2003; Peters et al., 2007). In this regard, attractiveness ratings of faces and voices (Feinberg et al, 2005), bodies and voices (Hughes et al., 2002; Hughes et al., 2004) as well as faces and body odours (Rikowski and Grammer, 1999; Cornwell et al., 2004) were positively correlated with one another. For example, Thornhill and Grammer, (1999) presented photographs of female faces and the nude bodies of the same women separately and asked male participants to rate the faces or bodies for attractiveness. They found positive correlations between the attractiveness ratings given for faces and bodies, and concluded that men in general see women's bodies and faces similarly in terms of physical attractiveness. Rikowski and Grammer (1999) reported positive correlations between female facial attractiveness and body odour attractiveness. Collins and Missing (2003) found that women judged higher on facial attractiveness by men, also received higher vocal attractiveness judgements. Related to the idea that people's faces and voices might both signal the same underlying quality, Feinberg (2008) suggested that faces and voices both can be considered as markers for hormonal status, because oestrogen positively correlates with female fertility (Baird et al., 1995). Additionally, the use of multiple attractiveness signals increases the accuracy of assessment of a potential mate (Møller and Pomiankowski, 1993). In conclusion, attractiveness perceptions of women's faces, body odours and voices have been studied extensively, particularly in the relationship to males mate preferences. Additionally, it has been shown that attractiveness ratings of different traits in the same women are correlated with each other. Studies assumed that the male preference for attractive female traits like faces, body odours and voices may be sexually selected and that attractiveness possibly enhances mating success because it signals reproductive potential.

\section{AIMS AND HYPOTHESES}

A review of studies on visual, olfactory, and vocal cues to female fertility reveals two things: First, the majority of studies on this topic was done with College age students, i.e., women aged some 18-30 years (as participants), and men of similar ages (as judges). These studies captured only a certain age cohort during women's 
reproductive life span, namely the time of peak fertility, and did not consider the full reproductive age range. Second, a considerable number of studies have investigated female's sexual preferences and behaviour across the menstrual cycle and differences in men's perceptions. Inferences on the evolutionary significance of sensory cues to female reproductive potential are mainly based on these reports. Basically, sexually attractive features like women's faces, body odours and voices are thought to have evolved to function as cues of reproductive potential, which by definition is the individual's future reproductive potential or total expected reproductive success from the present time forward (Fisher, 1930; Williams, 1966). No study has yet examined the link between sexual attractiveness of women's faces, body odours and voices in women of a larger age range. Hence, it was one of the aims of this study to investigate whether age-related differences in female's fecundity are encoded in women's facial, olfactory, and vocal quality. The present thesis used the terminology fecundity in consideration to the larger studied age-range of female participants. Fecundity refers to women's reproductive ability during the whole life span, whereas fertility states to the receptivity during the menstrual cycle.

This present thesis comprises three empirical studies. The first study (Chapter II) focussed on differences in men's perceptions of visual, olfactory, and vocal cues between women of three different age groups (e.g., young girls, adult women, circum-menopausal women), thus differing in their age-related reproductive potential. The second study (Chapter III) tested if visual and vocal cues in women signal the same quality, by looking at male and female visualizations of unfamiliar female voices. To get further evidence for the assumption that faces and voices are one ornament of same quality, the third study (Chapter IV) investigated male's ability to match concordant pairs of unfamiliar female faces and voices. The translation of vocal information into facial visualizations (Chapter III) as well the male matching performance of concordant face-voice pairs (Chapter IV) was tested with regard to differences between the three female age groups (young girls, adult women and circum-menopausal women).

The first study of this thesis (Chapter II) investigated differences of men's attractiveness and femininity judgements and tested the hypothesis that faces, body odours, and voices collected from adult women would be judged as more attractive 
and feminine than those collected from young girls and circum-menopausal women. The stimuli were collected from a total sample of 121 female participants aged 11 to 65 years. Literature on women's attractiveness has demonstrated that facial and vocal femininity increases women's perceived attractiveness, and that this is - at least in case of faces - a cross-culturally stable preference (Perrett et al., 1994, Jones et al., 1995). I predicted that adult women (reproductive age group) would receive higher attractiveness and femininity judgements of men than young girls (pre-reproductive age group) and circum-menopausal women (post-reproductive age group) and this would basically being true for male judgements given to female faces, body odours and voices. Female reproductive potential is a function of age, which is skewed in favour of youth. However, I did not necessarily expect a difference in perceived facial attractiveness and femininity between young girls and circum-menopausal women, as young girls' faces should appear to be "sexually immature". While this perceptual difference might be rather obvious for men's judgements of women's facial attractiveness, it seemed less clear for female body odour. However, given the hypothesis that female "quality" is also encoded in their body odour, I expected significant differences in men's attractiveness and femininity perceptions of female body odour, particularly between adult woman and young girls as well as adult women and circum-menopausal women. Similarly, I hypothesised that men would judge voices of adult women higher on attractiveness and femininity than those of young girls and circum-menopausal women. While it has been found that voices of older people are lower pitched than voices of younger people (Ryan, 1972; Zenker, 1964; Sweeting \& Baken, 1982; Orlikoff, 1990), I did not necessarily expect significant differences between the young girls and circum-menopausal women for the same reason as with faces and body odours. The voices of young girls from the pre-reproductive group should appear too "childlike", and therefore sexually immature, and those of the circum-menopausal women may receive lower attractiveness ratings because of their lower pitched voices ("masculinization"), which will together likely result in non-significant difference in men's attractiveness ratings between these two age groups.

From the literature it is known that femininity is influenced by oestrogen and therefore, feminine faces were preferred, presumably because they indicated fertility and appeared to be more attractive compared to less feminine faces. The same logic 
has been applied to findings that women with higher pitched voices, which are also influenced by oestrogen levels (Abitbol et al., 1999), received higher femininity and attractiveness judgements than women with lower pitched voices (Feinberg et al., 2008) and to findings, that facial attractiveness correlated positively with vocal attractiveness (Collins and Missing, 2003). Thus the second study (Chapter III) tested differences in facial visualizations of female and male participants of unfamiliar women's voices of the three age groups, to get further support for the assumption that in humans, like in many other species, mate choice is dependent upon multiple signals because they all are developmentally influenced by oestrogen (Abitbol et al., 1999; Feinberg et al., 2008; Law-Smith et al., 2006). I hypothesized that female and male listeners would be able to isolate femininity and age-related variations out of unfamiliar female voices and "translate" this information into facial visualizations. Related to cross-modal preferences for female faces and voices, I expected age-related judgments of voice recordings, with those of adult women being judged as more attractive and feminine compared to those of young girls and circum-menopausal women. Additionally, I expected that facial visualizations to the voices of adult women appearing more feminine than those indicated to the voices of the young girls and circum-menopausal women. To expand on the assumption that attractiveness in women correlates across different modalities and males' ability to integrate age-related variations in female facial and vocal information, I tested males' ability to match concordant face-voice pairs of women in order to get further evidence for the assumption that faces and voices are on ornament signalling same quality (Chapter IV).

The present thesis aims to contribute to the understanding of men's perception of age-related visual, olfactory, and vocal cues in women. The intention of the present study was the investigation of men's sensitivity to age-related variations in women's facial, olfactory, and vocal attractiveness with the assumption that facial, olfactory and vocal attractiveness is linked to women's fecundity. Accordingly, to report relationships between facial and vocal attractiveness and the assumption that both signal the same quality, the present thesis tested visual associations of female voices as well as males matching performance of concordant female face-voice pairs (for thesis outline see Figure 1). The results are discussed with reference to the evolutionary psychology framework. 


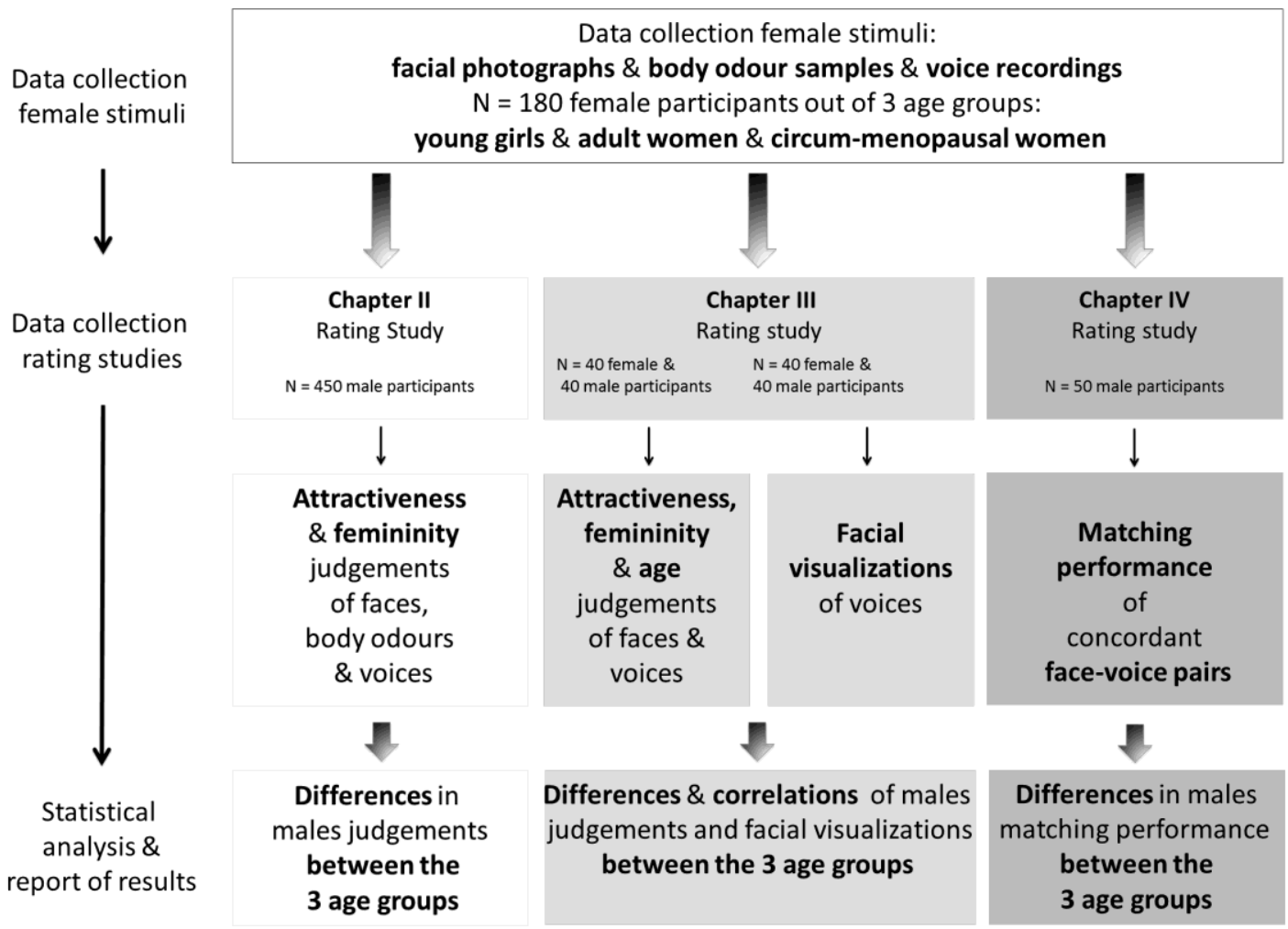

Figure 1: Graphic chart of the individual working steps. The present thesis comprises three Studies (Chapter II - IV), which focussed on age-related differences in female facial, olfactory and vocal attractiveness to test the hypothesis of visual, olfactory and vocal cues to female fecundity. 


\title{
FACIAL, OLFACTORY, AND VOCAL CUES
}

\section{TO FEMALE REPRODUCTIVE VALUE}

\author{
Susanne Röder ${ }^{1}$, Bernhard Fink ${ }^{1}$, Benedict C. Jones ${ }^{2}$
}

${ }^{1}$ Department of Sociobiology/Anthropology, University of Göttingen, Kellnerweg 6, D-37077 Göttingen, Germany.

${ }^{2}$ Institute of Neuroscience and Psychology, University of Glasgow, 58 Hillhead Street, Glasgow G12 8QB, United Kingdom.

Evolutionary Psychology (2013), 11(2), 392-404. 


\begin{abstract}
Facial, olfactory, and vocal cues may advertise women's fertility. However, most of the evidence for this proposal has come from studies of changes in young adult women's attractiveness over the menstrual cycle. By contrast with this emphasis on changes in attractiveness over the menstrual cycle, possible changes in women's attractiveness over their lifespan have received little attention. The present study investigated men's ratings of young girls' (11-15 years old), adult women's (19-30 years old) and circum-menopausal women's (50-65 years old) facial, body odor, and vocal attractiveness and femininity. Faces and voices, but not body odors, of young girls and adult women were perceived to be significantly more attractive and feminine than those of circum-menopausal women. These data suggest that facial and vocal cues may be cues to women's reproductive value, but that body odor cues do not necessarily advertise this information.
\end{abstract}

Keywords: women, face, body odor, voice, attractiveness, femininity, reproductive value 


\section{INTRODUCTION}

Some of the facial, olfactory, and vocal cues considered by men to be attractive in women may be preferred because they are associated with women's genotypic and/or phenotypic condition (Grammer, Fink, Møller, and Thornhill, 2003a; Thornhill and Gangestad, 2008). These preferences may then reflect adaptations for selecting mates with high reproductive value (Fisher, 1930). Consistent with this proposal, several studies have reported positive correlations between attractive facial characteristics in women and measures of their physical health (see Gray and Boothroyd, 2012, for a recent review). Additionally, body characteristics that are particularly important determinants of women's body attractiveness (e.g., their body mass index [Tovée and Cornelissen, 2001; Tovée, Hancock, Mahmoodi, Singleton, and Cornelissen, 2002], waist circumference and breast size [Jasiénska, Ziomkiewicz, Ellison, Lipson, and Thune, 2004]) are also associated with health measures (Flegal, Kit, Orpana, and Graubard, 2013). Many researchers have suggested that fertility may be a particularly important component of women's mate value (e.g., Gangestad and Thornhill, 2008; Grammer, Fink, Juette, Ronzal, and Thornhill, 2001, Grammer et al., 2003a; Symons, 1979, 1995). However, there is considerably less evidence for correlations between physical characteristics in women and fertility.

To date, the majority of studies that have investigated possible links between women's attractiveness and measures of their fertility have tested for changes in young adult women's attractiveness over the menstrual cycle (see Haselton and Gildersleeve, 2011 for a recent review). For example, studies have found that men judge face photographs (Puts et al., 2013; Roberts et al., 2004), recordings of women's voices (Bryant and Haselton, 2009; Pipitone and Gallup, 2008; Puts et al., 2013), and body odor samples (Gildersleeve, Haselton, Larson, and Pillsworth, 2012; Havlicek, Dvorakova, Bartos, and Flegr, 2006; Kuukasjärvi et al., 2004; Roberts et al., 2011; Singh and Bronstad, 2001) obtained during the fertile (i.e., late follicular) phase of the menstrual cycle to be more attractive than those obtained during lowfertility phases. Studies of men's perceptions of the facial and vocal attractiveness of women taking hormonal contraceptives did not find any of the above reported systematic differences across the menstrual cycle (see Alvergne and Lummaa, 2009, 
for a review), consistent with the proposal that these findings reflect associations between fertility and attractiveness. Although it is unclear whether changes in women's attractiveness during the menstrual cycle necessarily reflect signals of women's fertility (see Thornhill and Gangestad, 2008 for discussion), they complement findings from other research that has linked between-subject differences in young adult women's facial and body attractiveness to between-subject differences in their fertility, as estimated from measured hormone levels (face: LawSmith et al., 2006; body: Jasiénska et al., 2004).

The majority of research that investigated the relationship between women's attractiveness and fertility has done so in samples of young adult (i.e., college-aged) women. This emphasis on young adult women may be warranted because women's fecundity is generally highest between 18 and 25 years of age, at least in Western societies (Balasch, 2010; Wood, 1989). However, it is also clear that female fecundity is not limited to this life-stage but should rather be seen as a function of age (Pawlowski and Dunbar, 1999), beginning at menarche and ending at menopause. This raises the question of whether men's judgments of women's attractiveness are sensitive to these age-related changes in fertility.

The current research explored this question by investigating whether men judge the attractiveness of faces, body odors, and voices from three different groups of women (young girls, adult women, and circum-menopausal women) to be significantly different from one another. Given the inverse J-shaped relationship between age and fecundity (Jones and Lopez, 2006), we hypothesized that face, odor, and voice stimuli collected from circum-menopausal women would be judged to be less attractive than the other groups. Since previous work demonstrated that men's preferences for putative facial, olfactory, and vocal fertility cues are correlated across modalities suggests that men respond to fertility cues in these domains in similar ways (Collins and Missing, 2003; Feinberg et al., 2005; Fraccaro et al., 2011; Rikowski and Grammer, 1999; Röder, Fink, Feinberg, and Neave, 2013; Saxton, Burriss, Murray, Rowland, and Roberts, 2009; Thornhill and Grammer, 1999), we predicted similar patterns of results for men's judgments of women's facial, odor, and body attractiveness. In addition to investigating between-group differences in women's attractiveness, we also tested for between-group differences in men's 
perceptions of women's femininity. Since previous research suggests that femininity is an important determinant of women's attractiveness (Feinberg, DeBruine, Jones, and Perrett, 2008; Perrett et al., 1998), we predicted that analyses of men's ratings of women's femininity would show a similar pattern of results to our analyses of men's ratings of women's attractiveness.

\section{MATERIALS AND METHODS}

\section{Female participants}

Facial photographs, body odors and voice recordings were collected from a total sample of 121 heterosexual women from three different age groups: young girls ( $n=50$; age range $=11-15$ years, $M=13.76$ years, $S D=1.44$ years), adult women $(n$ $=42$; age range $=19-30$ years, $M=23.48$ years, $S D=2.47$ years) and circummenopausal women $(n=29$; age range $=50-65$ years, $M=56.83$ years, $S D=5.17$ years). Participants were recruited from the local population of Göttingen (Germany) and all reported to be native German speakers. To control for possible effects of exogenous hormones on attractiveness, only participants who reported not using any kind of hormonal contraceptive or supplements at the time of data collection were recruited. All participants received 30 euros financial compensation.

\section{Facial photographs}

A digital image of the face in front-view was taken of each woman under standardized light, from a fixed distance and with fixed focus, and against a constant black background. Images were captured using a 6.2-megapixel digital single-lens reflex camera (Canon EOS 500D) fitted with a Canon 55-200mm 1:4-5.6 lens (Canon Corporation, Tokyo, Japan) and stored in JPEG file format at a resolution of 3168 x 4752 pixels. The women were instructed to adopt neutral facial expressions and remove make-up, glasses and any other facial adornments (e.g., facial jewellery). All participants were asked to tie back their head hair with a black hair-band. In postprocessing, faces were isolated from remaining other visible features (such as hair and the neck) by colouring these features black in Adobe Photoshop CS3 (Adobe Systems Inc., San Jose, USA). Finally, all digital images were scaled to a resolution 
of 433 x 600 pixels for presentation in the rating component of the study.

\section{Body odor samples}

White cotton T-shirts were used for body odor collection, following previous protocols (e.g., Lenchova, Roberts, and Havlicek, 2009; Rikowski and Grammer, 1999; Singh and Bronstad, 2001). Each participant received a number coded bag containing one unworn white, $100 \%$ cotton T-shirt, a box of unscented washing powder for washing clothes and bed sheets, and a bottle of unscented body soap and hair shampoo. All T-shirts were washed with the same unscented washing powder before giving them to the participants and were then put into plastic zip bags immediately. Participants were instructed to refrain from using perfume, engaging in sexual activity, sharing their bed with another person (or their pet) for the three consecutive nights of wearing the T-shirt. They were also instructed not to eat onions, garlic or spicy foods during this period. They were further instructed to wash their bed sheets and pillow covers with the unscented washing powder before the three nights of wearing the T-shirt. Participants were told to use the unscented soap and hair shampoo for bathing or showering each evening to assure similar personal hygiene practices between participants. They were instructed to put the T-shirt back into the plastic bag each morning and take it out only before going to bed again. After three nights, participants were told to put back the T-shirt into the plastic bag, seal it and keep it in the freezer until their appointment with the experimenter. At this appointment, the bags with the T-shirts were collected and kept frozen at $-20^{\circ} \mathrm{C}$ until the body odor ratings took place. We checked reported compliance with experimenter instructions using protocols described in previous studies (Rikowski and Grammer, 1999; Singh and Bronstad, 2001; Thornhill and Gangestad, 1999) by asking female participants after completion of the body odor sampling procedure (via a questionnaire) to report any violations of the instructions, such as the use of perfume/deodorants, cigarette smoking, usage of provided unscented soap and shampoo. ANOVA statistics revealed that none of the requested possible violations of the protocol had a significant effect on men's perceptions of female attractiveness and femininity (all $F>.84$, all $p>.05$ ). 


\section{Voice recordings}

Voice recordings were collected with a unidirectional microphone (Rode NT1-A, with phantom power and Rode SM6 pop filter), positioned approximately 10 centimetres in front of the head of the participant, using computer software (Apple Logic Studio®; Apple Inc. Cupertino, USA) and at a sampling rate of $44.1 \mathrm{kHz}$ with 16-bit amplitude. A digital interface (M-AUDIO 8x8 Audio-/MIDI-Interface Fast Track $\left.{ }^{\circledR}\right)$ was used to encode the recording. Participants were requested to speak the five vowels (A [a], E [E], I [i], O [o], $\mathrm{U}[\mathrm{u}]$ ) repeatedly and for one minute. To ensure a constant speech rate, the vowels were presented visually on a computer screen in front of them (via a video clip), one after the other, and in two seconds intervals. Participants were asked to speak each vowel when it was presented on the screen. The serial order of the visual presentation of vowels changed six times within one minute of presentation in order to avoid habituation effects. For the subsequent rating study, a sequence of approximately nine seconds of the vowels I [i], E [E], O [o], U [u], A [a] (in that order), was digitally isolated from the entire stream and saved in MP3 audio format (Constant Bit Rate Mode, 128kbps).

\section{Rating studies}

Digital facial photographs, body odor samples (via T-shirts) and voice recordings were presented in three independent rating studies to a total sample of 450 male participants (age range $=18-40$ years, $M=23.84$ years, $S D=3.50$ years) and rated on attractiveness and femininity. All participants received 5 euros compensation for their time.

\section{Face and voice perceptions}

A panel of 150 men (age range $=18-40$ years, $M=23.68$ years, $S D=3.25$ years) rated 24 facial photographs that were randomly selected out of the total sample, 12 of them on attractiveness and another 12 on femininity. Attractiveness and femininity were rated in separate blocks of trials and trial order was fully randomized. Another 150 men (age range $=18-40$ years, $M=23.20$ years, $S D=2.97$ years) judged each a subset of 24 voice recordings on attractiveness and femininity using the same procedure. Medialab 2008 software (Empirisoft Inc., New York, 
USA) was used for face and voice presentation and ratings were made on a 5-point scale $(1=$ not at all attractive/feminine to $5=$ very attractive/feminine $)$. For the assessments of voice recordings participants listened to the samples using circumaural earphones (Superlux HD681F). All voice recordings were set to constant amplitude, and participants were instructed to judge the voices spontaneously as the samples were played only once before they were prompted to make a decision.

\section{Body odor perceptions}

A panel of 150 men (age range $=18-40$ years, $M=24.65$ years, $S D=4.04$ years) was recruited to judge the smell of 12 T-Shirts, randomly selected from the total sample, for attractiveness and femininity. The $\mathrm{T}$-shirt rating took place in separate sessions, over a time period of three weeks. At each session, 12 T-Shirts were defrosted three hours before the rating and put into 5 litre glass jars with clamp lids, numbered from 1 to 12 and judged by 10 participants. They were told to pick one jar after the other (the order differing between participants), shake it, open it and smell it without touching the T-Shirt, then rate the smell of the T-Shirt for attractiveness and femininity on a 5-point scale $(1=$ not at all attractive/feminine to 5 $=$ very attractive/feminine). Participants provided their ratings using paper questionnaires that were placed next to each jar.

\section{RESULTS}

A one-sample Kolmogorov-Smirnov test indicated that the mean values of men's attractiveness and femininity ratings for women's faces, body odors and voices within each age group did not show a significant deviation from the normal distribution (all $Z<1.12$, all $p>.17$ ).

To test for differences between mean values of men's judgements of women's facial, olfactory and vocal attractiveness and femininity, a series of analyses of variance (ANOVA) was conducted. Separate analyses were carried out for each combination of rating type (attractiveness or femininity) and characteristic (face, body odor, or voice). Mean ratings were the dependent variable and age group (young girls, adult women, circum-menopausal women) was the factor. 
Analyses showed a significant effect of age group for ratings of both facial attractiveness $\left(F=25.58, p<.001 ; \eta^{2}=0.30\right)$ and vocal attractiveness $(F=41.34, p$ $\left.<.001 ; \eta^{2}=0.41\right)$, but not for ratings of body odor attractiveness $(F=0.39, p=.68$; $\eta^{2}=.007$; Figure 1). For facial attractiveness, young girls received the highest attractiveness ratings $(M=2.12, S D=0.43)$, followed by that of adult women $(M=$ $1.91, S D=0.44)$, and circum-menopausal women $(M=1.43, S D=0.34)$. Both, young girls and adult women were judged to be significantly more attractive than circum-menopausal women (both $p<.001$ ), whereas the difference in attractiveness ratings between young girls and adult women was not quite significant $(p=.06)$. For vocal attractiveness, adult women received higher attractiveness ratings than did young girls and circum-menopausal women (adult women: $M=3.16, S D=0.49$; young girls: $M=2.78, S D=0.58$; circum-menopausal women: $M=1.99, S D=0.50$ ), and attractiveness ratings for each of the three groups differed significantly from one another $($ all $p<.01)$.

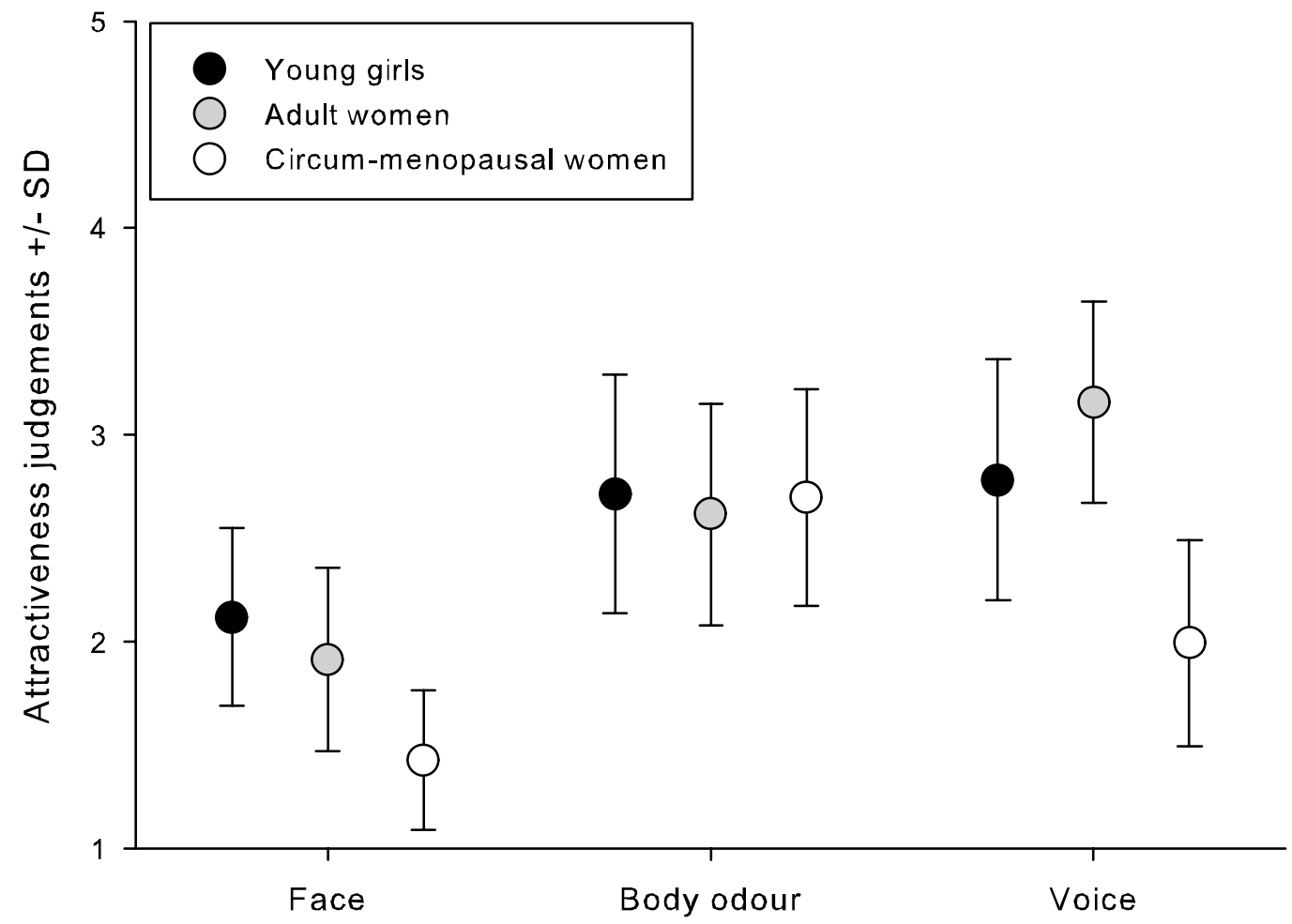

Figure 1: Men's attractiveness judgements of young girls, adult women's and circum-menopausal women's faces, body odours and voices. 
Pairwise comparisons of body odor attractiveness ratings between the age groups did not show any significant difference (all $p=.99$ ).

The ANOVAs for femininity ratings also showed a main effect of age group for ratings of women's faces $\left(F=8.49, p<.001 ; \eta^{2}=0.13\right)$ and voices $(F=33.12, p$ $\left.<.001 ; \eta^{2}=0.36\right)$, but not for ratings of body odors $\left(F=0.05, p=.96 ; \eta^{2}=0.0008\right.$; Figure 2). Faces of young girls received higher femininity ratings than those of adult women and circum-menopausal women (young girls: $M=3.16, S D=0.56$; adult women: $M=2.83 S D=0.57$; circum-menopausal women: $M=2.67, S D=0.47$ ).

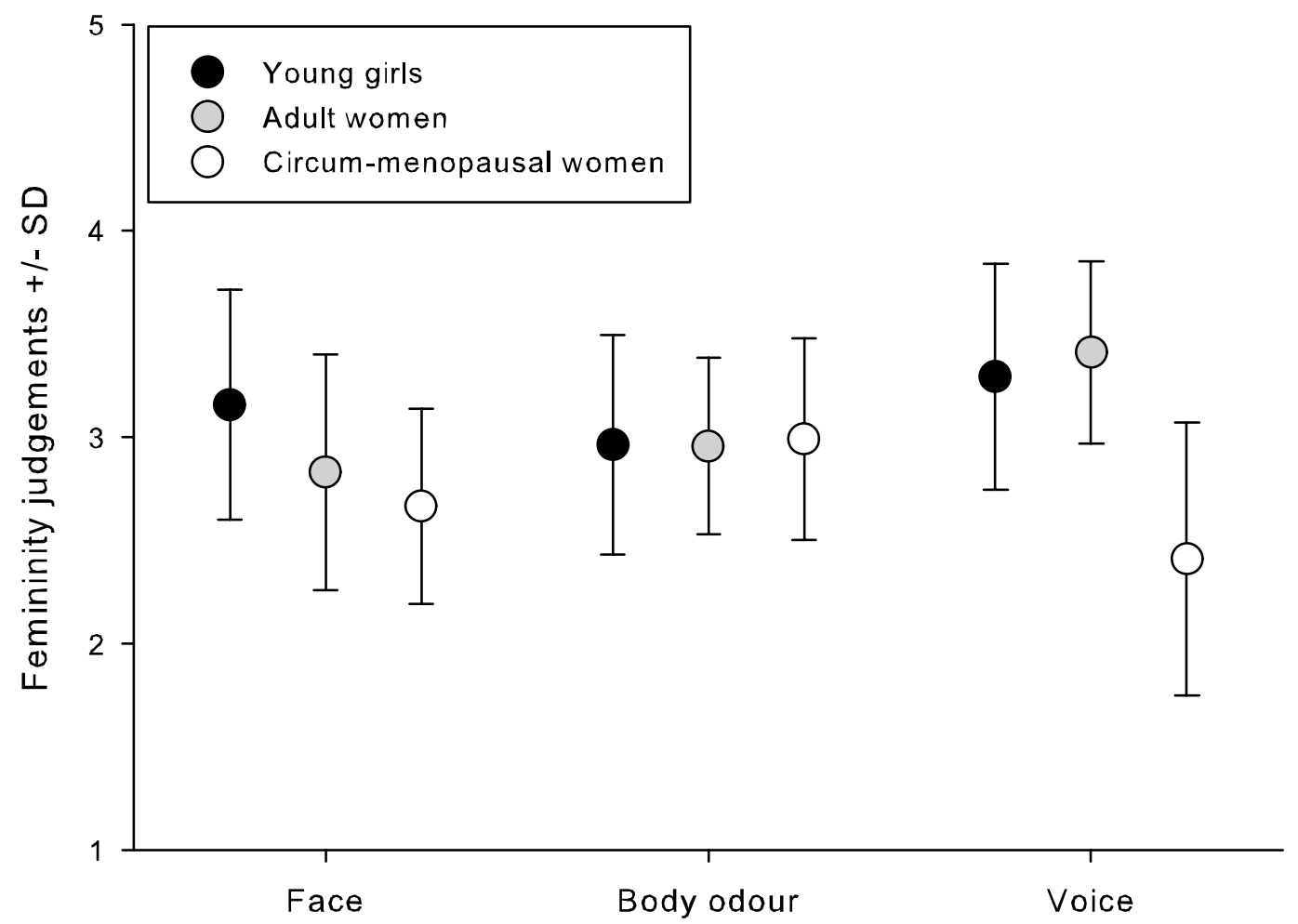

Figure 2: Men's femininity judgements of young girls, adult women's and circummenopausal women's faces, body odours and voices.

Pairwise comparisons showed that femininity ratings of young girls' faces were significantly higher than those of adult $(p<.05)$ and circum-menopausal women's faces $(p<.001)$, but that adult women and circum-menopausal women did 
not differ in rated femininity $(p=.63)$. Analyses also showed that vocal femininity ratings of adult women were higher than those of young girls and circummenopausal women (adult women: $M=3.41, S D=0.44$; young girls: $M=3.29, S D=$ 0.55 ; circum-menopausal women: $M=2.41, S D=0.66$ ). Pairwise comparisons showed that femininity ratings of circum-menopausal women's voices were significantly lower than those of young girls' or adult women's voices (both $p$ $<.001$ ), but no significant difference between femininity ratings of young girls' and adult women's voices $(p=.91)$. Pairwise comparisons of body odor femininity ratings between the age groups did not show any significant difference (all $p>.05$ ).

Female age was positively correlated with vocal attractiveness in the group of young girls $(r=.49, p<.001)$ and negatively correlated with vocal attractiveness in the group of adult women $(r=-.39, p<.05)$. The correlation between age and vocal attractiveness in the group of circum-menopausal women was not significant, however $(r=.08, p=.69)$. Although female age was also positively correlated with facial attractiveness in the group of young girls $(r=.31, p<.05)$, it did not predict facial attractiveness in the groups of adult $(r=.04, p=.81)$ or circum-menopausal $(r$ $=-.30, p=.12$ ) women. Female age did not correlate with body odor attractiveness in any of the three groups (all absolute $r<.24$, all $p>.10$ ).

\section{DISCUSSION}

The aim of the present study was to investigate the significance of women's faces, body odors and voices as cues to age-related differences in female reproductive value. We studied men's perceptions of the attractiveness and femininity of these features in three groups of women: young girls, adult women, and circum-menopausal women. Our results show that men judged the attractiveness and femininity of young girls and adult women to be significantly higher than that of circum-menopausal women. However, we did not detect significant differences in attractiveness and femininity assessments of body odor among the three groups of women. Thus, our results suggest that both women's faces and voices provide cues to women's reproductive value, but also indicate that body odor may not necessarily provide similar information about women's age-linked fertility. Moreover, there 
were differences in regard to men's attractiveness and femininity perception of women's faces and voices, particularly for the group of young girls and adult women. Young girls' faces were judged to be more attractive and feminine than those of adult women while adult women's voices were judged to be more attractive and feminine than those of young girls. These latter results suggest that men's perceptions of women's vocal and facial attractiveness may be more closely tied to femininity than youth, per se (see also, e.g., Feinberg et al., 2008). Indeed, among the group of young girls, age was positively correlated with both facial and vocal attractiveness, suggesting more mature girls may be judged as more attractive.

Studies of the role of facial, olfactory and vocal cues in human mate preferences and choice have suggested that certain features in women are particularly attractive to men because they signal aspects of women's phenotypic and genotypic condition (Grammer et al., 2003a; Thornhill and Gangestad, 2008). Health and youth are considered to be the predominant qualities men employ in their assessment of female attractiveness and femininity because of their link with fertility and reproductive value (Grammer et al., 2003a; Wood, 1989). Most evidence for this proposal has come from studies of young adult women (typically college-age students), although the hypothesis receives additional support from the medical literature on age-related changes in female endocrinology and the associated decline of fecundity (e.g., Jones and Lopez, 2006). Evolutionary psychologists have suggested that men are sensitive to even subtle hormone-related changes in female facial, olfactory or vocal characteristics (e.g., those occurring across the menstrual cycle), and there is accumulating evidence that this is indeed the case (see Haselton and Gildersleeve, 2011 for a recent review). A typical finding is that men judge women's faces, voices, and also body odor collected during the fertile phase of the menstrual cycle higher on attractiveness than those obtained during low-fertility phases (but see Mitro, Gordon, Olsson, and Lundström, 2012 for people's ability to discriminate age based on body odor).

Our data expand on these studies of men's sensitivity to female menstrual cycle related changes in facial appearance, body odor and voice quality by investigating men's attractiveness and femininity assessments of women from three age groups that cover a larger age range than was the case in previous studies. 
Considering a women's life span, it is obvious that, although female fecundity declines with age, it is not limited to a certain period in early adulthood (Pawlowski and Dunbar, 1999). Nonetheless, we hypothesized that the pattern of differences in men's perception of the attractiveness of facial, vocal, and olfactory cues in different groups of women (young girls, adult women, and circum-menopausal women) would be similar to that reported in studies comparing fertile and non-fertile phases of the menstrual cycle, such that circum-menopausal women would be judged to be less attractive and feminine than the other groups. This hypothesis was supported by our data for attractiveness and femininity judgements of female faces and voices, but not for the assessment of body odor. While this latter null result clearly does not imply that body odor conveys no information about women's reproductive value, it does seem to contrast with Mitro et al. (2012), who reported that humans are sensitive to age-related intensity of body odor and that this relates to pleasantness ratings. Fundamental differences in the design of our and Mitro et al.'s studies may explain this discrepancy, however. For example, Mitro et al. (2012) collected 'supra-donor' stimuli by combining body odor samples from same-sex and same-age group individuals, in order to control for the potential effects mediated by individual body odor, while our study presented individual samples of body odor to men and considered mean ratings in the statistical analysis. In addition, Mitro et al. (2012) found that participants' ability to extract age-related cues from body odor depends on the sex of the donor, such that participants' discrimination performance was higher for male body odor than for female body odor whilst pleasantness ratings were higher for female body odor than for male body odor. Except for the difference in pleasantness ratings of middle-age (45-55 years) and old-age women's (75-95 years) body odor (the former being rated as more pleasant), no other significant differences were detected with female donors. The difficulty in detecting age-related differences, especially in female body odor, may explain our finding of no significant differences in attractiveness and femininity rating among the three age groups.

Although some studies of women's vocal and facial attractiveness have found that women's voices and faces may be more attractive around ovulation than during other phases of the menstrual cycle (Bryant and Haselton, 2009; Roberts et al., 2004), other studies have not observed this pattern of results (e.g., Bleske-Rechek et al., 2011; Fischer et al., 2011). Our data showing that circum-menopausal women's 
voice and faces are perceived to be less attractive than those of women with greater reproductive potential, together with other recent work linking vocal and facial attractiveness to measured hormone levels in adult women (Puts et al., 2013), present converging evidence for the proposal that women's facial and vocal attractiveness are cues to their reproductive potential, even if evidence from studies exploring the effects of fertility over the menstrual cycle may be equivocal.

An interesting result of this present study is that men's attractiveness and femininity assessments of young girl's faces were highest whereas with voices adult women received the highest ratings. There is probably more than one way to interpret this finding and in lack of additional attributes and/or hormonal data from our female participants we can only speculate on the actual cause that has created it. We did not ask male judges to explicitly rate sexual attractiveness of the women when presenting their faces, body odor and voices. Thus, the highest ratings of facial attractiveness and femininity of young girls may be explained by a general aesthetic assessment, which is likely influenced, but not necessarily caused, by the mating context. We hypothesize that this result could be an expression of the fundamental selection pressure operating on male assessments of female quality, resulting in preferences for features that signal youth rather than a true preference for young girls' faces. On the contrary, women's voices may be a more accurate cue to female fecundity than faces, given that men's judgements of adult women's vocal attractiveness in particular were highest. With reference to age-related hormonal effects (particularly around puberty and menopause) upon female faces and voices, it seems sensible to conclude that the strength of these actions favour voice over facial attractiveness when it comes to the assessment of female fecundity.

In summary, our data show that female facial and vocal attractiveness (but not body odor) serve as age cues and suggest that men are sensitive to these cues when assessing women's attractiveness and femininity. In considering women of three age groups, i.e., young girls, adult women, and circum-menopausal women, we found a significant effect of age group on men's assessments of female facial and vocal femininity, which was primarily driven by less positive ratings for circummenopausal women. Furthermore, our data suggest a general preference for female youth, which finds differential expression in terms of attractiveness and femininity 
assessments of women's faces and voices. In considering the strong link between age and fertility in women, we propose that facial and vocal cues may serve as cues to female reproductive value and that voice quality may particular advertise fecundity. Future studies should employ hormonal data and render men's assessments of female features more precisely (e.g., by comparing attractiveness judgments in mating and prosocial contexts) in order to disentangle mate preferences from other forms of evaluation. Such studies could also more carefully consider the possible effects of the type of relationship for which men judged female attractiveness (e.g., long-term versus short-term, platonic versus sexual) and the possible role that cosmetic procedures may have in influencing perceptions of women's reproductive value, particularly when assessing the attractiveness of older women.

Acknowledgements: This project was funded by the German Science Foundation (DFG), grant number FI 1450/6-1, awarded to B.F., as well as through the Institutional Strategy of the University of Göttingen. Tessa Cappelle provided helpful comments on an earlier version of the manuscript.

Received 30 April 2013; Revision submitted 31 May 2013; Accepted 31 May 2013. 


\title{
FACIAL VISUALIZATIONS OF WOMEN'S VOICES SUGGEST A CROSS-MODALITY PREFERENCE
}

\section{FOR FEMININITY}

\author{
Susanne Röder ${ }^{1}$, Bernhard Fink ${ }^{1}$, David R. Feinberg ${ }^{2}$, Nick Neave ${ }^{3}$ \\ ${ }^{1}$ Department of Sociobiology/Anthropology, University of Göttingen, Kellnerweg 6, \\ D-37077 Göttingen, Germany. \\ 2Department of Psychology, Neuroscience and Behavior, McMaster University, \\ Hamilton, Ontario, Canada L8S 4K1. \\ ${ }^{3}$ Department of Psychology, Faculty of Health \& Life Sciences, Northumbria \\ University, Newcastle upon Tyne, NE1 8ST, UK.
}

Evolutionary Psychology (2013), 11(1), 227-237. 


\section{ABSTRACT}

Women with higher-pitched voices and more feminine facial features are commonly judged as being more attractive than are women with lower-pitched voices and less feminine faces, possibly because both features are affected by (age-related) variations in endocrine status. These results are primarily derived from investigations of perceptions of variations in single-modality stimuli (i.e., faces or voices) in samples of young adult women. In the present study we sought to test whether male and female perceptions of women's voices affect visual representations of facial femininity. Eighty men and women judged voice recordings of 10 young girls (11-15 years), 10 adult women (19-28 years) and 10 peri-/post-menopausal women (50-64 years) on age, attractiveness, and femininity. Another 80 men and women were asked to indicate the face they think each voice corresponded to using a video that gradually changed from a masculine looking male face into a feminine looking female face. Both male and female participants perceived voices of young girls and adult women to be significantly younger, more attractive and feminine than those of peri-/post-menopausal women. Hearing young girls' and adult women's voices resulted in both men and women selecting faces that differed markedly in apparent femininity from those associated with peri-/post-menopausal women's voices. Voices of young girls had the strongest effect on visualizations of facial femininity. Our results suggest a cross-modal preference for women's vocal and facial femininity, which depends on female age and is independent of the perceiver's sex.

Keywords: age, attractiveness, face, femininity, perception, voice, women. 


\section{INTRODUCTION}

Previous research has shown that men are remarkably sensitive to variations in women's facial morphology and voice quality, both of which are linked to female age and fertility (see for review Feinberg, 2008; Puts, Jones, and DeBruine, 2012). Evolutionary psychologists, therefore, propose that preferences for certain female facial and vocal characteristics have evolved through sexual selection pressures operating on male perceptions in order to identify high quality mates. According to this logic, these preferences are expressed in the form of positive attractiveness perceptions, which is thought to reflect men's assessments of key features that play a role in mate selection (for review see Fink and Penton-Voak, 2002; Gangestad and Scheyd, 2005).

Studies on men's perceptions of women's facial and vocal characteristics (among others) have repeatedly demonstrated that attractiveness judgments are strongly correlated with age (e.g., Buss, 1989; Rhodes, 2006) and femininity assessments (e.g., Jones et al., 1995; Perrett, May, and Yoshikawa, 1994;), possibly because both features are associated with estrogen levels (Abitbol, Abitbol, and Abitbol, 1999; Feinberg, DeBruine, Jones, and Perrett, 2008; Law-Smith et al., 2006), and thus reflect reproductive potential. Facial features that correspond to high estrogen levels include a small chin, high cheekbones, full lips and large round eyes (Johnston and Franklin, 1993; Jones et al., 1995; Schaefer et al., 2006). Vocal fundamental frequency, which is perceived as voice pitch, is a sexually dimorphic feature with the average woman's voice pitch being around twice as high as that of the average man (Titze, 1994). This sex difference seems to be strongly associated with the differential production of the sex steroids testosterone and estrogen during the pubertal years (Abitbol et al., 1999); the larynx being particularly sensitive to the variation in these hormones (Caruso et al., 2000). Voices of older people differ from those of younger people (Orlikoff, 1990; Ryan, 1972; Sweeting and Baken, 1982; Zenker, 1964), and voice pitch tends to decrease with increasing maturity, being positively related to changes in estrogen levels in women (Abitbol et al., 1999; Feinberg et al., 2006). Indeed, women's vocal attractiveness is negatively associated with perceived age (Collins and Missing, 2003; Feinberg et al., 2008). 
Thus, several studies have demonstrated positive associations between voice pitch and men's attractiveness ratings of natural women's voices (Collins and Missing, 2003; Feinberg et al., 2008; Fraccaro et al., 2011; Puts, Barndt, Welling, Dawood, and Burriss, 2011). Furthermore, other studies have systematically manipulated recordings of women's voices by altering voice pitch, thus creating feminized and masculinized versions of them. Collectively, these studies have found in Canada, the US, UK, and among the Hadza (a hunter-gatherer group in Tanzania), that men judged the feminized versions of voices as more attractive than masculinized versions (Apicella and Feinberg, 2009; Feinberg et al., 2008; Jones, Feinberg, DeBruine, Little, and Vukovic, 2008, 2010; Klofstad et al., 2012; O’Connor et al., 2011; Re, O’Connor, Bennett, and Feinberg, 2012).

In women, facial and body morphology and voice quality seem to be correlated across modalities (Feinberg et al., 2005; Grammer, Fink, Juette, Ronzal, and Thornhill, 2001). For example, women whose faces were rated as attractive also received higher attractiveness judgments of their bodies (Thornhill and Grammer, 1999). Similarly, Collins and Missing (2003) reported that women with attractive faces tend to also have attractive voices. These authors found that digital facial photographs of women with high-pitched voices were perceived to be more feminine and younger than photos presented with low-pitched voices. Therefore, male preferences for multiple traits like visual and vocal femininity are thought to be adaptive, since both indicate health and youth (Bryant and Haselton, 2009; Vukovic, Feinberg, DeBruine, Smith, and Jones, 2010). Researchers propose that multiple ornaments may have evolved, in part, to reduce the risk of being deceived when relying on a single cue or signal (Møller and Pomiankowski, 1993). The assumption here is that facial and vocal characteristics reflect the same underlying trait, i.e., sexhormone levels (Feinberg, 2008), and the consistency in preferences for these traits may reduce the effects of noise and error perceptions of the qualities (see also Grammer et al., 2001).

Although many studies have investigated the relationship between vocal and facial attractiveness (e.g., Collins and Missing 2003; Feinberg et al., 2008), most research has mainly focused on attractiveness perception of faces or voices presented in isolation, and thus considered only single modality stimuli. Only one study to date 
has presented voices and faces manipulated in masculinity simultaneously (O'Connor et al., 2011) and found no interactions among vocal and facial attractiveness ratings. With regard to the wide range of variations in females' voice pitch, affected by age-related hormonal changes during a woman's life span (for review see Amir and Biron-Shental, 2004), we hypothesized that listeners isolate femininity and age-related variation out of unfamiliar female voices and translate this information into a facial visualization. Related to cross-modality preferences for female faces and voices, we expected (i) age-related judgments of voice recordings, with those of younger women being judged as younger, more attractive and feminine, and (ii) facial visualizations of the sound of younger women to appear more feminine.

\section{MATERIALS AND METHODS}

\section{Participants}

Our sample was 30 female participants of three age groups, i.e., 10 young girls (11-15 years, $\mathrm{M}=14.30 ; \mathrm{SD}=1.25), 10$ adult women (19-28 years, $\mathrm{M}=23.40$; $\mathrm{SD}=2.59)$ and 10 peri-/post-menopausal women $(50-64$ years, $\mathrm{M}=55.80 ; \mathrm{SD}=$ 4.85), who were recruited from a larger scale project on female sexual signals. All claimed to be German native speakers, non-smokers, and not having a cold or facial injury (e.g., a broken nose) that could have affected their individual voice quality. None reported to be taking any kind of hormonal medication (e.g., hormonal contraceptives or hormonal supplements).

\section{Voice recordings}

Voices were recorded with a unidirectional microphone (Rode SM6, with phantom power and pop filter), positioned approximately 10 centimeters in front of the mouth, using computer software (Apple Logic Studioß), in mono and at a sampling rate of $44.1 \mathrm{kHz}$ with 16-bit amplitude quantization. We used a digital interface (M-AUDIO 8x8 Audio-/MIDI-Interface Fast Track®) to encode the sounds. Female participants were requested to speak the five vowels (A [a], E [ $\varepsilon$ ], I [i], O [o], $\mathrm{U}[\mho])$ repeatedly and for 1 minute. To ensure a constant speech rate, the vowels were presented visually on a computer screen in front of them (via a video clip), one 
after the other, and in 2-second intervals. Participants were asked to speak each vowel at the time it was presented on the screen. The serial order of the visual presentation of vowels changed six times within 1 minute of presentation in order to avoid habituation. For the subsequent rating study, a sequence of some 9 seconds of

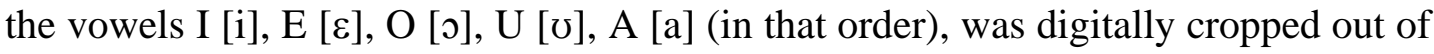
the entire stream and saved in MP3 audio format (Constant Bit Rate Mode, 128kbps, Stereo).

\section{Voice ratings}

A sample of 80 participants (40 men and 40 women) aged 18 to 40 years (M $=24.46, \mathrm{SD}=3.79$ ) listened to the vocal samples via circum-aural earphones (Superlux HD681F), set to constant amplitude, and judged them on age, attractiveness and femininity (in blocks, with voices randomized within each block). These presentations were created using Medialab software (Empirisoft Inc., New York, USA). All participants were recruited from the local student population in Göttingen (Germany) and reported to be German native speakers. Age estimations were provided using a free input field with accepted values set to a range of 1 to 99 years. Judgments of attractiveness and femininity were made on a 7-point scale $(1=$ not attractive/feminine to $7=$ very attractive/feminine). Participants were instructed to judge the voices spontaneously and told that they would hear every voice only once in order to make their decision. All participants received a payment of $5 €$ for their participation. We used the mean ratings of age, attractiveness and femininity of all participants for the statistical analysis.

\section{Facial visualizations}

A further 80 participants (40 men and 40 women) aged 18 to 33 years $(\mathrm{M}=$ $23.40, \mathrm{SD}=3.37$ ) listened to the vocal samples (randomized between participants) using the same technical setup as for the voice ratings, while watching a 1200 frames video clip (40 seconds at a rate of 30 frames per second) showing an extremely masculine looking male face (frame 0) that gradually changed into an extremely feminine looking female face (frame 1200) (Johnston, Hagel, Franklin, Fink, and Grammer, 2001). In this video, facial characteristics such as symmetry and hairstyle are kept constant, so that the predominant visual change is due to apparent 
masculinity/femininity. Participants were asked to indicate the face they felt each voice corresponded to, by moving the slider in the video time line forward and backward to that face. They were instructed to type in the face (frame) number using a free input field in Medialab. Voices were played in a loop until participants made a decision and clicked 'continue' to proceed. For the statistical analysis, we used the calculated means of frame numbers corresponding to each voice, as indicated by the participants.

\section{RESULTS}

Table 1 reports descriptive statistics of female and male participants' age, attractiveness, and femininity perceptions of women's voices. There was a significant main effect of age group for all three attributes (age: $F=487.21$; attractiveness: $F=103.00$; femininity: $F=29.52$; all $p<.001$ ), with voices of young girls and adult women being perceived as significantly younger, more attractive and feminine than those of peri-/post-menopausal women. Omnibus post-hoc comparisons of age groups for the three attributes revealed significant effects throughout, with two exceptions: attractiveness and femininity perceptions of young girls' and adult women's voices did not differ significantly from one another (attractiveness: $p=.11$; femininity: $p=.99$ ).

Participants' sex did not have a main effect on perception of women's voices (age: $F=.88, p=.35$; attractiveness: $F=.47, p=.49$; femininity: $F=.69, p=.41$ ). There was a significant age group * sex interaction effect for attractiveness perception of women's voices $(F=3.78, p<.05)$, but no significant effect for age and femininity (age: $F=1.49, p=.23$; femininity: $F=.36, p=.63$ ). While men perceived the voices of young girls as relatively higher on the attractiveness scale, women did not. Female participants judged voices of adult and peri-/postmenopausal women higher on attractiveness than did male participants. 
Table 1: Descriptive statistics (M and SD) of female and male participants' age, attractiveness and femininity perceptions of women's voices.

\begin{tabular}{ccccccc}
\hline & \multicolumn{2}{c}{ Young } & \multicolumn{2}{c}{ Adult } & \multicolumn{2}{c}{$\begin{array}{c}\text { Peri-/Post- } \\
\text { menopausal }\end{array}$} \\
\cline { 2 - 7 } & Females & Males & Females & Males & Females & Males \\
\multirow{2}{*}{ Age } & 18.52 & 19.00 & 25.81 & 24.47 & 47.19 & 44.55 \\
& $(2.97)$ & $(3.84)$ & $(5.59)$ & $(6.36)$ & $(11.12)$ & $(9.88)$ \\
Attractiveness & 3.77 & 4.01 & 4.16 & 4.01 & 2.78 & 2.40 \\
& $(0.89)$ & $(0.92)$ & $(0.74)$ & $(0.80)$ & $(0.92)$ & $(0.85)$ \\
Femininity & 4.34 & 4.60 & 4.52 & 4.56 & 3.53 & 3.58 \\
& $(0.95)$ & $(1.06)$ & $(0.83)$ & $(0.73)$ & $(0.96)$ & $(1.16)$ \\
\hline
\end{tabular}

Pearson correlations $(r)$ of age, attractiveness and femininity perceptions of women's voices showed significant correlations of attractiveness and femininity perceptions in males $(r=.46, p<.01)$ and females $(r=.33, p<.05)$, but no significant relationships of both attributes with age perception in either sex (males: age and attractiveness $r=.05, p=.75$; age and femininity $r=-.18, p=.26$; females: age and attractiveness $r=.14, p=.37$; age and femininity $r=-.07, p=.65)$. Running these correlations for each of the three age groups separately revealed essentially the same results.

Table 2: Descriptive statistics (M and SD) of female and male participants' facial visualizations (in terms of frame numbers on the male to female video) of women's voices.

\begin{tabular}{lcccccc}
\hline & \multicolumn{2}{c}{ Young } & \multicolumn{2}{c}{ Adult } & \multicolumn{2}{c}{$\begin{array}{c}\text { Peri-/Post- } \\
\text { menopausal }\end{array}$} \\
\cline { 2 - 7 } & Females & Males & Females & Males & Females & Males \\
Frame & 916.35 & 893.26 & 896.14 & 871.15 & 722.63 & 702.06 \\
number & $(133.08)$ & $(136.24)$ & $(132.25)$ & $(123.07)$ & $(142.41)$ & $(168.52)$ \\
\hline
\end{tabular}


Table 2 reports descriptive statistics of male and female selections (in terms of frame numbers) of facial visualizations of women's voices. There was a significant main effect of age group $(F=110.07, p<.001)$ with participants assigning higher frame numbers (i.e., higher facial femininity) to the voices of young women as compared to those of adult and peri-/post-menopausal women. There was no significant difference in facial visualizations of women's voices from the young girls and adult women group ( $p=.22$ ), but both groups differed significantly from that of the peri-/post-menopausal group (both $p<.001$ ); the latter received significantly lower frame numbers, indicating less facial femininity (see Figure 1).
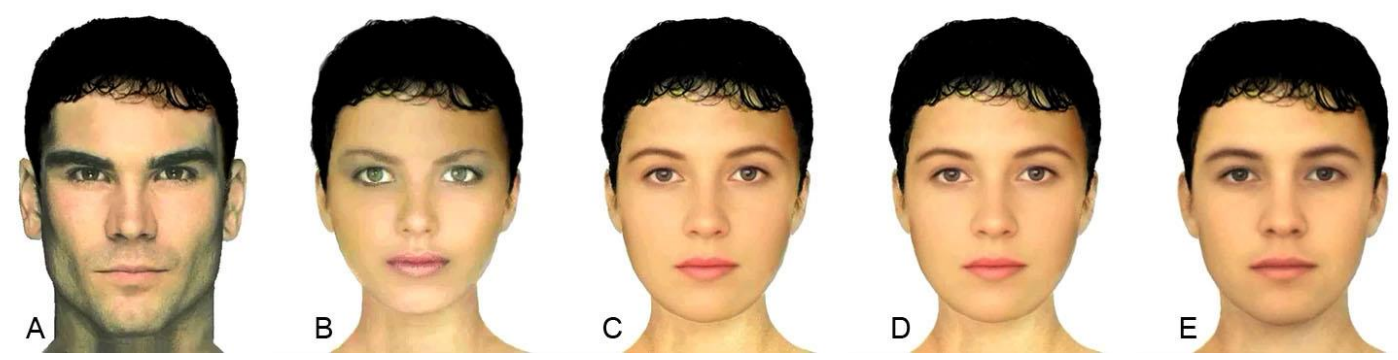

Figure 1: Facial visualizations of participants' perceptions of women's voices on the male to female movie ranging from A (frame 0) to B (frame 1200), and mean frame numbers (male and female responses together) of visualizations for the group of young girls (C, frame 904), adult women ( $\mathrm{D}$, frame 883) and peri-/post-menopausal women (E, frame 712).

Male and female participants did not differ significantly in their associations of faces on the continuum of masculine/feminine images corresponding to women's voices $(F=.74, p=.39)$. Also, we did not detect a significant interaction effect of age group $* \operatorname{sex}(F=.01, p=.98)$. 


\section{DISCUSSION}

One of the aims of the current study was to further understand people's age, attractiveness and femininity perceptions of women of different age groups, i.e., young girls, adult women, and peri-/post-menopausal women, as most related studies investigating perception of women's voices have studied college-age women. The groups in the current study were chosen as they represent characteristic ages through the female lifespan with regard to reproductive value (Buss and Schmitt, 1993). Overall, we found that the voices of young girls and adult women were perceived as being significantly younger, more attractive, and feminine than those of peri-/postmenopausal women. In comparison to female raters, male participants judged the voices of young girls to be more attractive, female raters perceived that adult voices were the most attractive. This may reflect differential selection pressures operating on female and male preferences, with males having evolved a stronger preference for youth than females. Although statistically significant, this effect was not very pronounced, and clearly requires further investigation in a larger sample than we had in the present study. We also acknowledge that the judgments could simply reflect the ages of the raters (aged 18-40) who were on average considerably younger than the women in the peri-/post-menopausal condition. These older voices might be rated more positively by an older group of raters, and future studies could address this issue.

Considering the relationships of people's age, attractiveness, and femininity judgments of women's voices, we found significant correlations in both male and female participants only for attractiveness and femininity, but neither of these attributes showed significant associations with age assessments. Thus, it seems that in evaluating vocal attractiveness of women, both females and males primarily rely on femininity perception. This result relates to previous findings reporting that vocal femininity predicts vocal attractiveness (Collins and Missing, 2003; Feinberg et al., 2008). Indeed, Feinberg et al. (2005) also found that ratings of vocal attractiveness were more related to perceptions of femininity than to perceptions of age. Nevertheless, the relationship of vocal femininity and attractiveness in women is thought to be moderated by age-related androgen and estrogen levels. Higher androgen levels are usually assumed with lower pitched voices (Abitbol et al., 1999; 
Feinberg et al., 2008) and there is evidence from systematic manipulations of voice pitch such that feminized versions of voices are perceived to be more attractive across societies (e.g., Apicella and Feinberg, 2009; Feinberg et al., 2008; Fraccaro et al., 2011; Jones et al., 2010; Puts et al., 2011). One limitation of this current study is that we did not measure circulating estrogen levels in our speaker sample, and so our suggestion that the changing preferences associated with age being dependent upon hormonal status remains speculative.

The second aim of our study was to investigate what people visualize when they hear unfamiliar voices. Previous research on the perception of women's voices has mainly focused on associations between physical measures and/or facial photographs with certain vocal characteristics (e.g., Collins and Missing, 2003; Feinberg et al., 2005; Hughes, Harrison, and Gallup, 2002) or facial composites based on objective measurements of women's voice pitch (Feinberg et al., 2005) and recorded people's preferences. These studies have shown that women with attractive faces also tend to have attractive voices, and that vocal and facial femininity positively predicts vocal and facial attractiveness (Collins and Missing, 2003; Feinberg et al., 2005, 2008; Puts et al., 2011). Collectively, these findings lend support to the theory that men's preferences for vocal and facial femininity are consistent across modalities because women's faces and voices advertise common information about the senders' hormonal status (Abitbol et al., 1999; Feinberg et al., 2005, 2008). Thus, it has been suggested that perceivers may use this cross-modal information in a way that may better inform their mate-choice decisions (see for review Feinberg, 2008).

Our results show that both men and women associate feminine looking faces with unfamiliar voices of young girls and adult women, but they tend to associate significantly less feminine looking faces with voices of peri-/post-menopausal women. As with age, attractiveness and femininity ratings of women's voices, this effect was largely driven by the significant difference between facial visualizations of young girls' and adult women's voices and those of the peri-/post-menopausal group. In short, listening to the sound of young voices causes men and women to visualize feminine faces. We therefore suggest that there is an age-related crossmodality preference for femininity that applies to both female faces and voices, and 
is applicable to both sexes, given previous and our present results of positive correlations of voice attractiveness and femininity. Our data did not show sex differences in female and male vocal judgments and facial visualizations, thus the potential consequences in terms of inter- and intra-sexual selection mechanisms remain to be investigated (see Puts et al., 2011). Indeed, O'Connor et al. (2011, 2012) show that women are more jealous of women with higher pitched voices, prefer their partners not spend time around women with higher pitched voices, and think that women with higher pitched voices are relatively more likely to cheat on their partners. Thus, prior work and the work presented here suggest that the relationship between women's voice frequencies and mate quality is important for both male choice and female competition.

On a proximate level, there is evidence from neurobiology/neuroimaging studies for a link between face and voice processing, suggesting functional coupling between face and voice areas (Love et al., 2011; von Kriegstein and Giraud, 2006). For example, Smith et al. (2007) provided evidence for sensory integration of auditory and visual information in the representation of human gender, suggesting that auditory information influences face perception and voice pitch may have an additional adaptive role of improving face recognition and perception. In that study, androgynous faces paired with low pitch in the male range were perceived as males, whereas when such faces were paired with tones in the female pitch range they were judged as females. In addition, neuroimaging studies have found that the two specific brain areas for face- and voice recognition (i.e., the fusiform face area and the superior temporal sulcus) have direct structural connections and can exchange information, which is especially relevant in the context of person identification (Blank, Anwander, Kriegstein, 2011). From an evolutionary perspective, the ability to compare and match visual and auditory stimuli could indeed help to adapt the relative weight of individual sensory modalities to overall perception, and thus reduce mate choice errors (see also Møller and Pomiankowski, 1993).

In summary, our data on age, attractiveness and femininity perceptions of women's voices add to those of previous studies by considering voices of three different age groups covering significant time periods in the female reproductive life span. We found that voices of peri-/post-menopausal women were perceived to be 
older, less attractive and less feminine than those of young girls and adult women, which may reflect a general adaptation towards the preference for youth. Our results support the hypothesis of matching information given by multiple signals, which is behaviourally relevant for optimizing human social perception.

Acknowledgements: This project was funded by the German Science Foundation (DFG), grant number FI 1450/6-1, awarded to B.F., as well as through the Institutional Strategy of the University of Göttingen. Two anonymous referees provided numerous valuable comments that helped improving an earlier version of the manuscript.

Received 28 November 2012; Revision submitted 30 January 2013; Accepted 8 February 2013. 


\section{WOMEN'S FACES AND VOICES:}

\section{ONE ORNAMENT OF QUALITY?}

Susanne Röder, Corinna Habenicht, Bernhard Fink

Department of Sociobiology/Anthropology, Institute of Zoology and Anthropology, University of Göttingen, Kellnerweg 6, D-37077 Göttingen, Germany

Unpublished data - Paper presented at the $25^{\text {th }}$ Annual Conference of the Human Behavior and Evolution Society 2013 in Miami Beach, Florida (USA). 


\begin{abstract}
It has been reported that perception of female facial attractiveness correlates positively with the attractiveness of their voices, possibly because both features are moderated by the same underlying qualities such as endocrinology. Thus, faces and voices may comprise one ornament of female quality. This hypothesis is however, mainly derived from correlational analyses of independent assessments of female facial and vocal attractiveness. In the present study, male participants listened to the voices of young girls, adult women and post-menopausal women, while they were prompted to identify the concordant face out of a face-pair presented on the screen Men's ability to identify concordant faces and voices was significantly higher than expected by chance for young girls and adult women, but not for post-menopausal women. We suggest that this reflects an adaptive cognitive mechanism in support of the (male) preference for (female) youth and discuss our results in context if the assertion that women's faces and voices comprise one ornament of quality.
\end{abstract}

Keywords: face, voice, perception, women, age, 


\section{INTRODUCTION}

Evolutionary psychologists propose that the male preferences for female visual and vocal features are adaptive, as it has been shown that both indicate health and youth (Bryant and Haselton, 2009; Vukovic et al., 2010). Research on women's facial and vocal attractiveness found that attractiveness judgements of both features are correlated with age (Rhodes, 2006; Röder et al., 2013a), and that women judged attractive for their faces were also judged attractive for their voices (Collins and Missing, 2003; Feinberg et al., 2005). In these studies, facial images of adult women with higher pitched voices were judged to be younger and more feminine than facial images of women with lower pitched voices. It is well documented that female attractiveness is correlated across multiple modalities. There is the hypothesis that multiple signals have evolved because the sensitivity of males and females to multiple signals can increase the accuracy of assessments (Møller and Pomiankowski, 1993). Being sensitive to multiple signals in the same way assumes the ability to match information given by different traits (e.g., faces and voices). This assumption has been supported by neurobiological studies, which reveal a functional coupling between the two brain areas that are responsible for processing facial and vocal information (von Kriegstein and Giraud, 2006; Love et al., 2011). Further evidence for the ability to integrate facial and vocal information was reported by Smith et al. (2006), showing that vocal information influence face perceptions. More recently, it has been shown that male and female participants associated unfamiliar voice samples of young girls and adult women with more feminine faces than voice samples of circum-menopausal women (Röder et al., 2013b).

Numerous studies have found that male judgements of female attractiveness are often related to cues signalling youthfulness, presumably because in women age is an important indicator of reproductive potential. These women, signalling youth and fertility should therefore be preferred as potential mate (Symons, 1979; Rhodes and Zebrowitz, 2002). Related to findings that women's facial and vocal attractiveness is influenced by age, as well as the assumption that both features signal the same quality, the present study investigated men's ability to match concordant face-voice pairs of women out of three age groups, in order to get further evidence 
for the assumption that males can match information given by different modalities because they signal the same quality.

\section{MATERIALS AND METHODS}

\section{Participants}

For the present study facial photographs and voice recordings of four young girls $(11-14$ years, $M=13.99 ; S D=1.41)$, four adult women $(18-23$ years, $M=$ $23.50 ; S D=0.58)$ and four circum-menopausal women $(51-65$ years, $M=58.75 ; S D$ $=5.91)$, were used as stimuli.

\section{Facial photographs}

A digital image of the face in front-view was taken of each woman under standardized light, from a fixed distance and with fixed focus, and against a constant black background. Images were captured using a 6.2-megapixel digital single-lens reflex camera (Canon EOS 500D) fitted with a Canon 55-200mm 1:4-5.6 lens (Canon Corporation, Tokyo, Japan) and stored in JPEG file format at a resolution of 3168 x 4752 pixels. The women were instructed to adopt neutral facial expressions and remove make-up, glasses and any other facial adornments (e.g., facial jewellery). All participants were asked to tie back their head hair with a black hair-band. In postprocessing, faces were isolated from remaining other visible features (such as hair and the neck) by colouring these features black in Adobe Photoshop CS3 (Adobe Systems Inc., San Jose, USA). Finally, within each age group, omnibus pairwise combinations were created (i.e., 12 per age group), resulting in a total set of 36 face pairs for presentation in the matching task of the study.

\section{Voice recordings}

Voices were recorded with a unidirectional microphone (Rode NT1-A, with phantom power and Rode SM6 pop filter), positioned approximately 10 centimetres in front of the mouth, using computer software (Apple Logic Studio®), in mono and at a sampling rate of $44.1 \mathrm{kHz}$ with 16-bit amplitude quantization. We used a digital interface (M-AUDIO 8x8 Audio-/MIDI-Interface Fast Track®) to encode the sounds. 
Following the protocols of previous studies (e.g., Collins and Missing, 2003; Feinberg et al., 2008), female participants were requested to speak the five vowels (A

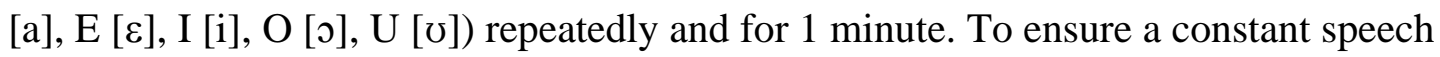
rate, the vowels were presented visually on a computer screen in front of them (via a video clip), one after the other, and in 2 seconds intervals. Participants were asked to speak each vowel at the time it was presented on the screen. The serial order of the visual presentation of vowels changed six times within 1 minute of presentation in order to avoid habituation. For the subsequent rating study, a sequence of some 9

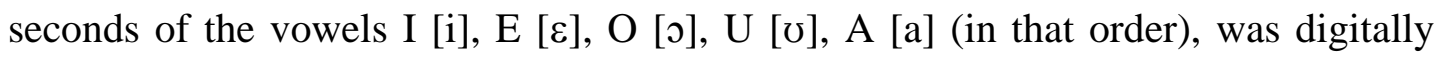
cropped out of the entire stream and saved in MP3 audio format (Constant Bit Rate Mode, 128kbps, Stereo).

\section{Matching task of faces and voices}

Fifty male participants aged 18 to 32 years $(M=22.88, S D=3.24)$ viewed the face-pairs, one after the other and in randomized order between the participants, while listening to the voice samples corresponding to only one face of each face pair, respectively. Participants listened to the vocal samples, set to constant amplitude and via circum-aural earphones (Superlux HD681F). They were instructed to indicate the concordant faces via mouse click on buttons (A or B), below each face. For the statistical analysis, we used the absolute frequencies of correct identified face-voice pairs per participant and within each age group.

\section{RESULTS}

A one-sample Kolmogorov-Smirnov test indicated that the mean values of men's matching performance of concordant identified face-voice samples within each age group did not show a significant deviation from normal distribution (all $Z<$ 0.90 , all $p>.14)$.

To test for differences between mean values of men's matching performance between the three female age groups, a repeated measures ANOVA was conducted with frequencies of correct identified face-voice pairs as within subject factor. The analysis of variance indicated that males' matching performance differed 
significantly between the three age groups $(F=12.33 ; p<.001)$. Males' ability to identify concordant female faces and voices was significantly higher for young girls than for adult and circum-menopausal women (both $p<.001$ ). There was no significant difference between the matching performance of adult women's faces and voices and those of circum-menopausal women (see Figure 1).

A one-sample $t$-test against the value of six (i.e., the assumption of identifying concordant face-voice samples in each of the three age groups just by chance) indicated that men's matching performance was significantly higher than expected by chance with faces and voices of young girls $(t=6.83, p<.001)$, but not with adult women $(t=1.07, p=.29)$ and circum-menopausal women $(t=-.84, p$ $=.41$; see Figure 1$)$.

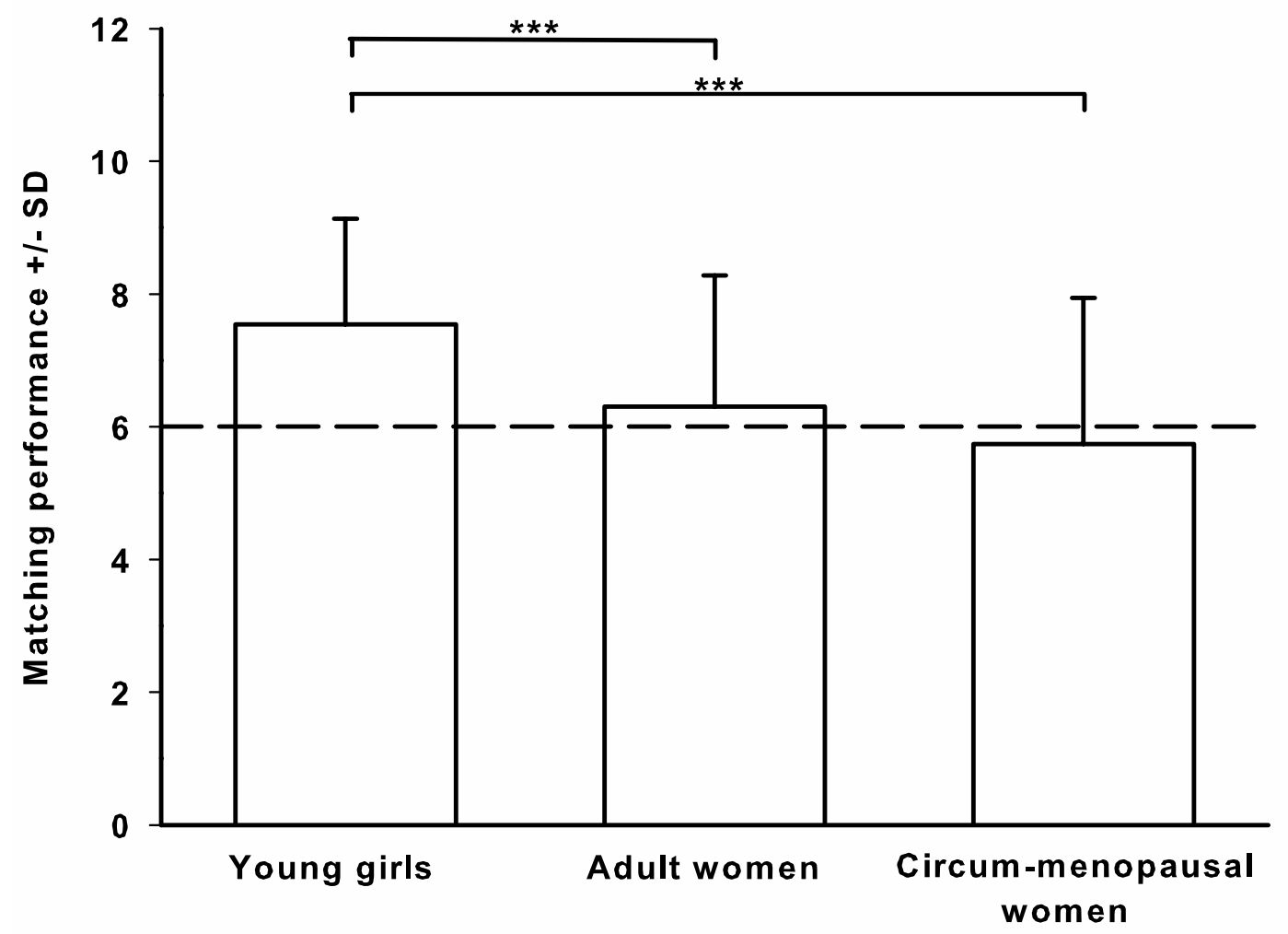

Figure 1: Mean frequencies of correctly identified face-voice pairs for the tree age groups. There were a maximum number of 12 correct face-voice pairs for each age group and per participant. The dashed, horizontal line indicates the level of correct identification by chance. 


\section{DISCUSSION}

The aim of the present study was to investigate men's ability to identify and match concordant female face-voice pairs out of different age groups (i.e., young girls, adult women and circum-menopausal women). Our preliminary data show that men's matching performance was significantly higher than expected by chance for the age group of young girls, but not for adult women and circum-menopausal women. Additionally, participants were significantly better in identifying concordant face-voice pairs of young girls compared to those of adult and circum-menopausal women. These results lend support to the assumption that faces and voices convey similar information and that the male ability to integrate this information depends on age of the woman.

This facility to integrate information from different modalities is supported by studies reporting a functional connection between the two specific brain areas, which are responsible for processing facial and vocal information (Love et al., 2011; von Kriegstein and Giraud, 2006). In this relation, Röder et al. (2013a) found that men and women associated more feminine looking faces when hearing unfamiliar voices of young girls and adult women than when hearing voices of circum-menopausal women. The latter were associated with less feminine looking faces. The authors concluded that this result supports the assumption that matching information given by multiple signals could be behaviourally relevant for optimizing social perceptions. It has been shown that women with attractive faces tend to also have attractive voices (Collins and Missing, 2003) and that facial morphology and voice quality are correlated (Feinberg et al., 2005), possibly because both features develop under the influence of oestrogen. They are thought to be one ornament signalling the same underling quality (Feinberg et al., 2005). The present thesis seems to support this assumption as the male ability to identify concordant face-voice pairs could indicate that faces and voices convey similar information about the senders' age. These findings agree with results of previous studies, which also found that raters are able to classify the age of unfamiliar persons based on facial photographs (Henss, 1991) as well as based on voice recordings (Collins \& Missing, 2003).

It has also been shown that faces and voices of older people were judged less attractive compared to those of younger people (Röder et al., 2013a, b; Henss, 1991). 
Males matching performance was highest for face-voice pairs of young girls, followed by adult women and circum-menopausal women, which is may be caused by the male preference for female youth. Youthfulness is known to be an important preference in male mate choice decisions presumably because in women age is one of the major indicators of reproductive potential (Symons, 1979; Rhodes and Zebrowitz, 2002). Thus, cues to youth are believed to be attractive. The assumption that males are attracted by female facial and vocal characteristics signaling youth seems to be supported by the present data as male participants were significantly better in identifying concordant face-voice pairs of young girls compared to those of adult and circum-menopausal women. It may appear contradictory that the highest male matching performance was not found for adult women, which is the age group where reproductive potential is highest. From the evolutionary point of view, males should be attracted by facial and vocal characteristics signalling high reproductive ability, which is higher in adult women than in young girls. This contradiction could be explained by the assumption that male participants estimated the age of the young girls based on the presented faces and voices as older, which has been also found in an earlier study (Röder et al., 2013a). In that study, male and female listeners estimated the age of young girls (chronological mean age $=14.30 ; \mathrm{SD}=1.25$ ) based on voice samples five years older than the speakers chronological age actually was. The possibility that males in the present study estimated the age of the young girls' also older could be explain the higher matching performance and would support the assumption that males are attracted by female facial and vocal characteristics that signal youth and fertility.

We interpret the male ability to identify concordant female faces and voices, especially in young girls as an expression of the selection pressure, which operated on males to identify female youth. In a recent study it was found that male participants judged voices of young girls and adult women higher on attractiveness than voices of peri-/post-menopausal women, which was also explained by the general male preference for youthful female features (Röder et al., 2013a). The present study focused on males matching performance of female face-voice pairs and did not ask for attractiveness assessments of the individual faces and voices. Thus, the assumption that the higher matching performance for face-voice pairs of young girls can be interpreted within the male preference for female youth remains 
speculative, and future research should include additional attractiveness estimations to get further support for this assumption.

Acknowledgements: This project was funded by the German Science Foundation (DFG), grant number FI 1450/6-1, awarded to B.F., as well as through the Institutional Strategy of the University of Göttingen. 


\section{GENERAL DISCUSSION}

From a sexual selection perspective, physical attractiveness in women serves as a cue to mate quality (Buss and Schmitt, 1993; Gangestad and Simpson, 2000; Symons, 1979), because it signals health and fertility (see Thornhill and Gangestad, 2008) and is linked to women's reproductive potential. Most evidence for the relationship between women's attractiveness and reproductive potential is derived from studies that tested attractiveness judgements of women's faces, body odours and voices in relation to menstrual cycle dependent changes in fertility. The aim of the present study was to investigate the significance of visual, olfactory, and vocal cues to female fecundity by testing age-related differences in women's attractiveness in a sample of a larger age range. The thesis aimed to demonstrate that male preferences for female attractiveness evolved, because female attractiveness signals youth and fecundity. To test this assumption, male judgements of women's facial, olfactory, and vocal attractiveness and femininity were collected of women out of three different age groups (pre-reproductive, reproductive and post-reproductive).

The first study (Chapter II) supports the notion that the male preference for facial attractiveness, and in particular for vocal attractiveness may be an adaptation, which facilitates males in identifying potential female mates with a high reproductive potential, namely adult women. However, no significant differences in attractiveness and femininity assessments of body odour among the three age groups of women were detected (Chapter II). The second study of this thesis provides further support for the assumption that in women visual and vocal cues are related, and seem to signal the same quality (Chapter III and IV). Results show that men associated voices of young girls and adult women with more feminine faces. Furthermore, males judged voices of adult women and young girls significantly higher on attractiveness than those of circum-menopausal women (Chapter II and III). Results reported in Chapter IV indicate that female faces and voices convey both same age-related information and males' ability to match concordant face-voice pairs 
of young girls, adult women and circum-menopausal women. Males were better in identifying concordant face-voice pairs of young girls and adult women compared to face-voice pairs of circum-menopausal women, which is interpreted as an expression of the selection pressure operating on males to identify female youth.

Male reproductive success is limited by getting access to fertile female mates. From the evolutionary point of view, men should therefore be sensitive to cues in women that signal youth and fecundity. However, evolutionary theories on human sexuality have been built around the claim that women have concealed ovulation and therefore have lost the distinct phase of "oestrus" (see Thornhill and Gangestad, 2008; Alexander and Noonan, 1979; Symons, 1979; Alexander, 1990). Contrary to this assumption, abundant evidence indicates now that men seem to be sensitive to even subtle hormone-related changes in female facial, olfactory or vocal characteristics (e.g., those occurring across the menstrual cycle; see Haselton and Gildersleeve, 2011 for a recent review). Evolutionary psychologists propose that this male ability to discern women who are able to reproduce from those women, who are not, could be beneficial in order to maximize their own reproductive success. Thornhill and Gangestad (2008) argued that selection pressures may have operated on women to suppress fertility cues (like sexual swellings in primates), but also on men to be sensitive to subtle cues indicating reproductive potential. Results from menstrual cycle studies show that women apparently exhibit a variety of signals of “oestrus" at mid cycle (Thornhill and Gangestad, 2008) as well as male's ability in detecting these signals of fertility-associated, physiological changes in women. No research has yet examined the relationship between attractiveness of women's faces, body odours and voices and age across a wide age range. Hence, it was focus of this present project.

\section{Face attractiveness}

One of the most robust findings on physical attractiveness is that males are mostly attracted to young looking faces with feminine proportions (see Thornhill and Gangestad, 2008). In that context, Law Smith et al. (2006) found that attractiveness, health and femininity ratings of males and females correlated positively with women's current oestrogen level. The authors argued that differences in facial attractiveness judgements are associated with changes in women's fertility. 
Additionally, feminine looking facial features appear to develop under the influence of oestrogen (Franklin et al., 1993; Fink et al., 2001). As facial attractiveness serves as a cue to women's reproductive potential, one purpose of the present thesis was to show that male participants would judge faces of adult women as more attractive than faces of young girls and circum-menopausal women, because in adult women the reproductive potential is highest (Chapter II). The present thesis shows that males judged the faces of adult women and young girls higher on attractive than those of circum-menopausal women. However, the results also indicate that men judged faces of young girls to be most attractive followed by those of adult and circum-menopausal women (Chapter II). These results do not confirm the assumption that adult women would receive highest attractiveness ratings, as males should be most attracted by facial cues signalling high reproductive potential. In a study conducted by Ebner (2008) it was also tested to see if the faces of younger (2029 years) and older (71-85 years) participants would be judged differently in terms of attractiveness and age. This study found similar results to those reported in chapter II. Faces of older women were rated less attractive and were estimated to be older compared to the faces of younger participants. Additionally, Jones (1995) found that women, whose facial proportions made them look younger than their actual age, were perceived as being more attractive by male raters recruited from five different populations. Jones (1995) proposed that the male attraction for visual cues signalling youth might be adaptive, insofar as it leads them to find younger women more attractive than older women. There is some evidence that facial maturation already peaks somewhat before age of maximum fertility (Symons, 1979; Jones, 1995; see Thornhill and Gangestad, 2008), which supports the findings that young girls received higher facial attractiveness judgements than adult women (Chapter II).

Women's voices may also contain qualities that have been sexually selected as cues to fecundity, as certain voice qualities are sexually dimorphic (e.g., women have a higher voice pitch than men) and appear to be influenced by sex-specific ratios of androgen and oestrogen (Abitbol et al., 1999). As with faces, women's voices develop under the influence of sex hormones with the onset of puberty and become less attractive with age (Collins and Missing, 2003), which is caused by the age-related decline in oestrogen. It has been also reported that women's voice attractiveness changes during the menstrual cycle. Female voice samples were 
perceived to be more attractive when collected during the high fertile days than voices samples collected during the non-fertile days. These findings lead to the assumption that women's vocal attractiveness as along with facial attractiveness is a cue to female fertility. In accord with the assumption that men should be attracted by vocal cues indicating high reproductive potential, the present thesis investigated males' sensitiveness to age-related differences in women's voices. I hypothesised that adult women would receive higher vocal attractiveness judgements than young girls and circum-menopausal women. The data presented in Chapter II confirm this assumption, as male participants judged the voice samples of adult women significantly higher on attractiveness than those of young girls and circummenopausal women.

These results suggest that vocal attractiveness seems to be a more accurate indicator of women's age than facial attractiveness. Several studies focussed on the female and male raters' ability to assess the age of others solely on hearing their voices. The authors found only small differences between the estimated age and the chronological age of the speakers (Lass et al., 1982). Male listeners were also able to differentiate between voice samples of young women and women older than 65 years (Ptacek and Sander, 1966). During the aging process, a number of physical and hormonal changes occur and influence the quality of men and women's voices. In human females, with onset of puberty, a surge of sex hormones (e.g., oestrogen in women) leads to the transition from a child-sounding voice, to a mature, adultsounding voice (Mendes-Laureano et al., 2006) caused by a decrease in voice pitch (Abitbol et al., 1999). With the onset of menopause, the decreasing activity of these sex hormones causes a further decrease in women's voice pitch, which leads to the assumption that age can be identified from voices (Shipp and Hollien, 1969). From the evolutionary point of view, the link between voice pitch and sex hormones, as well as the ability to make accurate age assessments of other individuals, may be important for males in order to detect young and fertile female mates. For men it would be reproductively beneficial to discern sexually mature women from those women advanced in age, because the remaining reproductive potential in younger women is higher than in older women (Hughes and Rhodes, 2010). The present findings show that men perceived voices of adult women and young girls as more attractive than those of circum-menopausal women, and are related to those reported 
by Hughes and Rhodes (2010). These authors also found that raters were most accurate in age assessments of younger age groups (10 to 15-year-olds, 16 to 22 year-olds and 23 to 34-year-olds) than age assessments of older age groups (46 to 55year-olds and 55 years and older). Accurate age assessments of women's voices may be essential for male mate choice to identify mature mates. Higher attractiveness ratings for adult women's voices compared to young girls voices and circummenopausal women's voices support the assumption that males are sensitive to agerelated differences in female voices and that voices may serve as a cue to female fecundity.

\section{Body odour attractiveness}

Researchers have found that woman's body odour is also an oestrogenmediated characteristic and serves additional to faces and voices, as a potential signal of reproductive potential. It has been found that body odour cues may provide information related to desirable qualities of a potential mate. A Study with seven couples who had long-term relationships reported that men rated the body odours (collected from saliva, underarms and loin) of their mates as more attractive when collected at mid-cycle compared to those collected during the non-fertile cycle days (Poran, 1994). Further studies investigated differences in women's body odour during the menstrual cycle found that men rated the smell of T-shirts worn by women on high fertile days as more attractive than the smell of T-shirts worn by women on days of low fertility (Havlicek et al., 2006; Kuukasjärvi et al., 2004). These results suggest that body odour is also linked to women's reproductive potential. According to this suggestion, it was part of the present thesis to test if body odour serves also as a cue to female fecundity (Chapter II). I hypothesised that male participants would judge the body odour samples of adult women as more attractive than body odour samples of young girls and menopausal women. The results presented in chapter II failed to detect age-related differences in women's body odour attractiveness. This suggests that body odour does not function as a cue to women's fecundity, since men did not perceive the body odours of adult women as more attractive than those of the young girls and the circum-menopausal women. The present findings suggest that fertility-associated variations across the menstrual cycle have a stronger effect on women's body odour than age-related variations 
during life span. Mitro et al. (2012) tested male and female ability to extract agedependent information out of body odour samples collected from men and women of different age groups (20-30 years; 45-55 years; $75-95$ years). The authors found that body odours of older people were rated as less intense and less pleasant than body odours collected from the younger age groups. However, Mitro et al. (2012) reported that participants were able to correctly assign age to body odours, but only for those originating from older-age individuals but not for body odours originating from younger age groups. This suggests that men and women are able to discriminate age based on body odour, but only for body odour samples of older individuals. A further study found that men and women responded differently to body odours. In this questionnaire-based study, women reported body odour in context of mate choice as a more important factor, whereas men in contrast considered visual cues as more important when choosing a potential mate (Havlicek et al., 2006). These could possibly explain why in the present study males did not judged body odour samples of adult women, young girls and circum-menopausal women different from each other. Furthermore, Thornhill and Gangestad (2008) proposed that not all oestrogenaffected signals, which attract male attention, could be interpreted as sexual selected cues to women's reproductive potential, but rather as by-products of hormonal changes. In a review article about human oestrus it was mentioned that women have probably evolved to conceal their oestrus what implies a reduction in the intensity of characteristics indicating fertility. The present data suggest that selection pressure has possibly operated on women to supress olfactory cues to fecundity, as male participants did not rate the body odours different between adult women, young girls and circum-menopausal women. To test the possibility, that menstrual cycleassociated hormonal changes have a stronger effect on women's body odour attractiveness as age-related changes, future research is needed.

\section{Attractiveness perception across different modalities}

Research has found that female attractiveness characteristics correlate positively with each other. It has been argued, that multiple signals provide better information about an individual's quality than individual signals. Recently, the investigation of multiple cues has received increasing attention and it has been shown that women who were perceived to be attractive for one trait (e.g., the face) 
were also perceived to be attractive for another trait (e.g., the voice). In a study of Collins and Missing (2003), participants were asked to rate female facial and vocal stimuli for attractiveness. The authors found a positive correlation between judged facial and vocal attractiveness. Additionally, it was reported that femininity is an important factor of women's attractiveness and that features indicating facial and vocal femininity are oestrogen-affected (Abitbol et al., 1999; Feinberg et al., 2006; Law Smith et al., 2006). Such findings led researcher to the suggestion that women's faces and voices may signal a common underlying quality (Feinberg et al., 2005; Feinberg, 2008).

This thesis investigated the assumption that in women visual and vocal cues are related and signal the same quality (Chapter III and IV). Results from Study II (Chapter III) relate to previous findings showing that vocal femininity predicts vocal attractiveness (Collins and Missing, 2003; Feinberg et al., 2008). The relationship between women's vocal attractiveness and femininity is thought to be moderated by differences in androgen and oestrogen levels. Higher levels of oestrogen are associated with higher pitched voices (Abitbol et al., 1999) and there is evidence from systematic manipulations of voice pitch such that feminized versions of voices are perceived to be more attractive (Apicella and Feinberg, 2009; Feinberg et al., 2008; Fraccaro et al., 2011; Jones et al., 2010; Puts et al., 2011). Positive correlations between vocal attractiveness and femininity perceptions (Chapter III) lend further support to previous findings that vocal femininity and vocal attractiveness are related. Results reported in chapter II also indicate a relationship between vocal attractiveness and femininity, in that the voices of adult women received not only highest attractiveness ratings, but also the highest femininity ratings, followed by young girls and circum-menopausal women. The same was found for facial attractiveness, faces judged higher on attractiveness (young girls), were also judged to be more feminine (Chapter II).

Findings presented in Chapter III indicate that male and female participants "extract" quality information (e.g., attractiveness, femininity) provided by an individual signal (voice) and "translate" it into another signal (face). Male and female participants associated unfamiliar voices of young girls and adult women with more feminine looking faces, and tended to associate circum-menopausal 
women's voices with faces appearing less feminine. The results suggest that there is an age-related cross-modality preference for attractiveness and femininity that applies to women's faces as well as to women's voices (Chapter III). The fact that male participants matching performance of concordant female face-voice pairs indicates also the human ability for matching information given by multiple signals, which could be behaviourally relevant for optimizing social perceptions (Chapter IV). The ability to match concordant faces and voices was significantly better than expected by chance within the age group of the young girls, which I suggest, reflects an adaptive cognitive mechanism in support of the male preference for female youth. Both studies (Chapter III and IV) provide further support for the assumption that female faces and voices signal age-related information and comprise one ornament of quality.

Collins and Missing (2003) reported that women with attractive faces also have attractive voices, which the present data do not support. In Chapter II, young adult women received the highest facial attractiveness and femininity judgements whereas adult women received the highest vocal attractiveness and femininity judgements. Related to the assumption that faces and voices signal the same underling quality, our data show that compared to faces, voices appear to be a more accurate cue to women's fecundity, as males judged voices of adult women most attractive followed by voices of young girls and circum-menopausal women. Related to results showing that the female voice seems to be a more accurate cue to women's fecundity, future research should investigate possible chronological differences in females' facial and vocal onset of maturity. It could be possible that rising oestrogen levels affect facial maturity earlier than vocal maturation, which may explain why the faces of young girls received higher attractiveness judgements whereas for voices, adult women received highest attractiveness judgements. Future research should furthermore investigate in male participants' age estimations of female participants based on facial photographs and voice recordings, as preliminary data indicate that male participants estimated the age of young girls based on facial photographs approximately five years older than their actual age was. Older age estimations could also account to the unexpected result, that males judged faces of young girls higher on attractiveness than faces of adult women. 


\section{Conclusion}

The present findings provide further support for the assumption that visual and vocal attractiveness features signal youth and are linked to women's fecundity. Results show that women's facial and vocal attractiveness, but not body odour attractiveness, varies between the three age groups and therefore seems to be affected by age. I conclude, that female faces and voices function as a cue to women's fecundity as male participants judged faces and voices of younger participants (young girls and adult women) more attractive and feminine than faces and voices of circum-menopausal women. This study is the first showing that males are sensitive to age-related differences in women's facial and vocal attractiveness considering a larger age-range. Previous researches on human sexuality and mate preferences have assumed that women evolved to supress signals of fecundity to ensure for example paternity care. Additionally, selection pressure has operated on males' ability to be sensitive to subtle cues in females, which signal youth and fecundity. In light of results indicating that men are indeed sensitive to differences in women's attractiveness during the menstrual cycle, Thornhill and Gangestad (2008) argue that this longstanding assumption should be reconsidered. Results of the present thesis provide further support for this assumption, as male participants seem to be attracted by facial and vocal characteristics signalling youth, which is associated with higher reproductive potential. In women fecundity is associated with oestrogen and a function of age. However, to what degree the age-related differences in women's attractiveness can be associated with hormonal differences, remains notional and future research is needed. One limitation of this current study is that we did not measure circulating oestrogen levels in our female sample, and so our suggestion that the changing preferences associated with age being dependent upon hormonal status remains speculative. Following studies should investigate in hormonal measurements as well as in correlations between perceived facial, olfactory and vocal attractiveness and measurements like voice pitch, waist-to-hip ratio and body mass index, all of which are known to be developmentally influenced by oestrogen. Further studies should also more carefully consider the possible effects of the type of relationship for which men judged female attractiveness (e.g., long-term versus short-term, platonic versus sexual) and should ask male participants for age estimations based on facial photographs, body odour samples and vocal samples. 


\section{SUMMARY}

Evolutionary psychologists argue that human males have evolved preferences for certain female characteristics that signal youth and health and consider them attractive. While menstrual cycle studies demonstrated changes in males perception of women's attractiveness between fertile and non-fertile menstrual cycle days, research on human mate preferences supposes that attractiveness in women is linked to female reproductive potential. No studies have yet addressed the significance of women's visual, olfactory and vocal attractiveness associated with age-related changes in women's reproductive potential by considering a larger age range. The present thesis focussed on age-related differences in facial, olfactory and vocal attractiveness in women of three age groups. To test for possible age-related differences in attractiveness, facial photographs, body odour samples and voice recordings from young girls (pre-reproductive), adult women (reproductive) and circum-menopausal women (post-reproductive) were collected and judged for attractiveness and femininity. Circum-menopausal women were judged less attractive for her faces and voices than young girls and adult women. No age-related difference in women's body odour attractiveness was found between the three age groups. The present thesis lends furthermore support to the assumption that faces and voices of women signal same quality, and that both convey information about the senders age. This thesis provides also evidence for the assumption that faces and voices of women serve as cues to reproductive potential since men perceived young girls and adult women's faces and voices more attractive than those of circummenopausal women. Women's voices seem to be a more accurate cue to female fecundity since adult women received highest attractive judgements. In conclusion, female voices and faces seem to be cues to women's fecundity since males are sensitive to age-related differences in women's vocal and facial attractiveness, but not body odour attractiveness. To what extend these differences in women's attractiveness are associated with hormonal changes occurring during women's reproductive life span remains speculative. 


\section{ZUSAMMENFASSUNG}

Evolutionspsychologen zufolge haben Männer Präferenzen für weibliche Merkmale entwickelt, die Gesundheit und Jugendlichkeit signalisieren. Aufgrund von Studien, die Veränderungen in Attraktivitätsbeurteilung von Frauen zwischen den fertilen und nicht-fertilen Tagen eines Menstruationszykluses berichteten, besteht die Annahme, dass in der Partnerwahl weibliche Merkmale im Zusammenhang mit dem Fortpflanzungspotential einer Frau stehen. Bisher hat jedoch noch keine Studie untersucht inwieweit visuelle, geruchliche und stimmliche Attraktivität von Frauen mit altersbedingten Unterschieden im Fortpflanzungspotential variieren. Die vorliegende Arbeit untersuchte Unterschiede in visueller, geruchlicher und stimmlicher Attraktivität von Frauen aus drei Altersgruppen. Es wurden Fotographien der Gesichter, Körpergeruchsproben und Stimmenaufnahmen von jungen Mädchen (pre-reproduktive Gruppe), Frauen (reproduktive Gruppe) und Frauen im menopausalen Alter (post-reproduktive Gruppe) aufgenommen und anschließend von männlichen Probanden nach Attraktivität und Weiblichkeit beurteilt. Gesichter und Stimmen von menopausalen Frauen wurden unattraktiver beurteilt als jene von den jungen Mädchen und Frauen. Es wurden keine Unterschiede in der Attraktivitätsbeurteilung des Körpergeruchs zwischen den drei Altersgruppen festgestellt. Die Ergebnisse zeigen außerdem, dass Gesichter und Stimmen ähnliche Informationen über eine Person vermitteln, die Rückschlüsse auf das Alter zulassen. Diese Arbeit stützt die Annahme, dass Gesichter und Stimmen ein Hinweis auf weibliche Fruchtbarkeit geben, da Männer die Gesichter und Stimmen der Probandinnen aus den beiden jüngeren Altersgruppen attraktiver beurteilten als jene der menopausalen Frauen. Weibliche Stimmen scheinen im Vergleich zu Gesichtern ein genaueres Merkmal für Fruchtbarkeit zu sein, da Frauen aus der reproduktiven Altersgruppe am attraktivsten beurteilt wurden. Zusammenfassend lässt sich sagen, dass Gesichter und Stimmen als Indikator für das reproduktives Potential bei Frauen dienen, da Männer scheinbar sensibel für altersbedingte Unterschiede in der Attraktivität von weiblichen Gesichtern und Stimmen waren. Inwieweit diese Unterschiede in der Attraktivitätsbeurteilung im Zusammenhang mit hormonellen Veränderungen stehen bleibt jedoch vorerst noch spekulativ. 


\section{REFERENCES}

Abitbol, J., Abitbol, P., and Abitbol, B. (1999). Sex hormones and the female voice. Journal of Voice, 13, 424-446.

Alexander, R. D. (1990). How did humans evolve? Reflections on the unique species. Special publication 1, Museum of Zoology, The University of Michigan, Ann Arbor.

Alexander, R. D., and Noonan, K. M. (1979). Concealment of ovulation, parental care, and human social evolution. In N. A. Changon and W. G. Irons (Eds), Evolutionary Biology and Human Social Behavior: An Anthropological Perspective. Duxbury Press, North Scituate.

Alvergne, A., and Lummaa, V. (2009). Does the contraceptive pill alter mate choice in humans? Trends in Ecology \& Evolution, 25, 171-179.

Amir, O., and Biron-Shental, T. (2004). The impact of hormonal fluctuations on female vocal folds. Current Opinion in Otolaryngology \& Head \& Neck Surgery, 12, 180-184.

Andersson, M. (1994). Sexual Selection. Princeton, Princeton University Press.

Apicella, C. L., and Feinberg, D. R. (2009). Voice pitch alters mate-choicerelevant perception in hunter-gathers. Proceedings of the Royal Society of London B, 276, 1077-1082.

Baird, D. D., McConnaughey, D. R., Weinberg, C. R., Musey, P. I., Collins, D. C., Kesner, J. S., et al. (1995). Application of a method for estimating day of ovulation using urinary estrogen and progesterone metabolites. Epidemiology, $6,547-550$.

Balasch, J. (2010). Ageing and infertility: an overview. Gynecological Endocrinology, 26, 855-60.

Barber, N. (1995). The Evolutionary Psychology of Physical Attractiveness: Sexual Selection and Human Morphology. Ethology and Sociobiology, 16, 395-424.

Blank, H., Anwander, A., and von Kriegstein, K. (2011). Direct structural connections between voice- and face recognition areas. The Journal of Neuroscience, 31, 12906-12915.

Bleske-Rechek, A., Harris, H. D., Denkinger, K., Webb, R. M., Erickson, 
L., and Nelson, L. A. (2011). Physical cues of ovulatory status: a failure to replicate enhanced facial attractiveness and reduced waist-to-hip ratio at high fertility. Evolutionary Psychology, 9, 336-353.

Broekmans, F. J., Knauff, E. A. H., te Velde, E., Macklon, N. S., and Fauser, B. C. (2007). Female reproductive ageing: current knowledge and future trends. Trends in Endocrinology and Metabolism, 18, 58-65.

Bryant, G. A., and Haselton, M. G. (2009). Vocal cues of ovulation in human females. Biology Letters, 5, 12-15.

Burley, N. (1979). The evolution of concealment of ovulation. American Naturalist, 11, 835-858.

Buss, D. M. (1989). Sex differences in human mate preferences: Evolutionary hypotheses tested in 37 cultures. Behavioral and Brain Science, 12, 149.

Buss, D. M. (1994). The Evolution of Desire - Strategies of Human Mating. New York, Basic books.

Buss, D. M. (2008). Evolutionary psychology: the new science of the mind ( $3^{\text {rd }}$ ed.). Boston: Allyn \& Bacon.

Buss, D. M., and Schmitt, D. P. (1993). Sexual strategies theory: an evolutionary perspective on human mating. Psychological Review, 100, 204-232.

Caruso, S., Roccasalva, L., Sapienza, G., Zappala, M., Nuciforo, G., and Biondi, S. (2000). Laryngeal cytological aspects in women with surgically induced menopause who were treated with transdermal estrogen replacement therapy. Fertility and Sterility, 74, 1073-1079.

Collins, S. A., and Missing, C. (2003). Vocal and visual attractiveness are related in women. Animal Behavior, 65, 997-1004.

Cornwell, R. E., Boothroyd, L., Burt, D. M., Feinberg, D. R., Jones, B. C., Little, A. C., et al. (2004). Concordant preferences for opposite-sex signals? Human pheromones and facial characteristics. Proceedings of the Royal Society of London B, $271,635-640$.

Dunson, D. B., Baired, D. B., Wilcox, A. J., and Weinberg, C. R. (1999). Day-specific probabilities of clinical pregnancy based on two studies with imperfect measures of ovulation. Human Reproduction, 14, 1835-1839.

Ebner, N. C. (2008). Age of face matters: age-group differences in ratings of 
young and old faces. Behavior Research Methods, 40, 130-136.

Fedigan, L. M., and Pavelka, M. S. M. (1994). The Physical Anthropology of Menopause. In A. Herring and L. Chan (Eds.), Strength in Diversity a Reader in Physical Anthropology. Toronto, Canadian Scholars Press.

Feinberg, D. R. (2008). Are human faces and voices ornaments signalling common underlying cues to mate value? Evolutionary Anthropology, 17, 112-118.

Feinberg, D. R., DeBruine, L. M., Jones, B. C., and Perrett, D. I. (2008). The role of femininity and averageness of voice pitch in aesthetic judgments of women's voices. Perception, 37, 615-623.

Feinberg, D. R., Jones, B. C., DeBruine, L. M., Moore, F. R., Law Smith, M. J., Cornwell, R. E., et al. (2005). The voice and face of woman: one ornament that signals quality? Evolution and Human Behavior, 26, 398-408.

Feinberg, D. R., Jones, B. C., Law Smith, M. J., Moore, F. R., DeBruine, L. M., Cornwell, R. E., et al. (2006). Menstrual cycle, trait oestrogen level, and masculinizy preferences in the human voice. Hormones and Behavior, 49, 215-222.

Fink, B., Grammer, K., and Matts, P. J. (2006). Visible skin color distribution plays a role in the perception of age, attractiveness, and health in female faces. Evolution and Human Behavior, 27, 433-442.

Fink, B., Grammer, K., and Thornhill, R. (2001). Human (Homo sapiens) facial attractiveness in relation to skin texture and color. Journal of Comparative Psychology, 115, 92-99.

Fink, B., Hugill, N, and Lange, B. P. (2012). Women's body movements are potential cue to ovulation. Personality and Individual Differences, 53, 759-763.

Fink, B., and Penton-Voak, I. S. (2002). Evolutionary psychology of facial attractiveness. Current Directions in Psychological Science, 11, 154-158.

Fischer, J., Semple, S., Fickenscher, G., Juergens, R., Kruse, E., Heistermann, M., and Amir, O. (2011). Do women's voices provide cues of the likelihood of ovulation? The importance of sampling regime. PLoS One, 6, e24490.

Fisher, R. A. (1930). The Genetical Theory of Natural Selection. Oxford University Press, Oxford.

Flegal, K. M., Kit, B. K., Orpana, H., and Graubard, B. I. (2013). Association of all-cause mortality with overweight and obesity using standard body mass index categories: a systematic review and meta-analysis. JAMA, 309, 71-82. 
Følstad, I., and Karter, A. (1992). Parasites, bright males, and the immunocompetence handicap. The American Naturalist, 139, 603-622.

Fraccaro, P. J., Jones, B. C., Vukovic, J., Smith, F. G., Watkins, C. D., Feinberg, D. R., et al. (2011). Experimental evidence that women speak in a higher voice pitch to men they find attractive. Journal of Evolutionary Psychology, 9, 57-67.

Gangestad, S. W., and Scheyd, G. (2005). The evolution of human physical attractiveness. Annual Review of Anthropology, 34, 523-548.

Gangestad, S. W., and Simpson, J. A. (2000). The evolution of mating: Trade-offs and strategic pluralism. Behavioral and Brain Sciences, 23, 675-687.

Gangestad, S. W., and Thornhill, R. (2008). Human oestrus. Proceedings of the Royal Society of London B, 275, 991-1000.

Geary, D. C., Vigil, J., and Byrd-Craven, J. (2004). Evolution of Human Mate Choice. Journal of Sex Research, 41, 27-42.

Gordon, C. M., and Laufer, M. R. (2005). Physiology of puberty. In S. J. H. Emans, D. P. Goldstein, and M. R. Laufer, (Eds.), Pediatric and Adolescent Gynecology. Philadelphia, Lippincott, Williams \& Wilkins.

Gildersleeve, K. A., DeBruine, L., Haselton, M. G., Frederick, D. A., Penton-Voak, I. S., Jones, B. C., and Perrett, D. I. (in press). Shifts in women's mate preferences across the ovulatory cycle: a critique of Harris (2011) and Harris (2012). Sex Roles.

Gildersleeve, K. A., Haselton, M. G., Larson, C. M., and Pillsworth, E. G. (2012). Body odor attractiveness as a cue of impending ovulation in women: Evidence from a study using hormone-confirmed ovulation. Hormones and Behavior, 61, 157-166.

Grammer, K., and Thornhill, R. (1994). Human facial attractiveness and sexual selection: The roles of averageness and symmetry. Journal of Comparative Psychology, 108, 233-242.

Grammer, K., Fink, B., Juette, A., Ronzal, G., and Thornhill, R. (2001). Female faces and bodies: n-dimensional feature space and attractiveness. In G. Rhodes and L. A. Zebrowitz (Eds.), Advances in visual cognition. Volume I: Facial attractiveness (pp. 91-125). London: Ablex Publishing. 
Grammer, K., Fink, B., Møller, A. P., and Thornhill, R. (2003a). Darwinian aesthetics: sexual selection and the biology of beauty. Biological Reviews, 78, 385-407.

Grammer, K., Fink, B., and Neave, N. (2005). Human pheromones and sexual attraction. European Journal of Obstetrics \& Gynecology and Reproductice Biology, 118, 135-142.

Grammer, K., Juette, A., and Fischmann, B. (1997). Der Kampf der Geschlechter und der Krieg der Signale. In B. Kanitscheider (Ed.), Liebe, Lust und Leidenschaft. Sexualität im Spiegel der Wissenschaft. Stuttgart, Hirzel.

Grammer, K., Keki, V., Striebel, B., Atzmueller, M., and Fink, B. (2003b). Bodies in motion: A window to the soul? In E. Voland and K. Grammer (Eds.), Evolutionary Aesthetics. Heidelberg, Springer.

Gray, A. W., and Boothroyd, L. G. (2012) Female facial appearance and health. Evolutionary Psychology, 10, 66-77.

Haselton, M. G., and Gildersleeve, K. (2011). Can men detect ovulation? Current Directions in Psychological Science, 20, 87-92.

Havlicek, J., Dvorakova, R., Bartos, L., and Flegr, J. (2006). Nonadvertized does not mean concealed: body odour changes across the human menstrual cycle. Ethology, 112, 81-90.

Henss, R. (1991). Perceiving age and attractiveness in facial photographs. Journal of Applied Social Psychology, 21, 933-946.

Hrdy, S. B. (1981). The woman that never evolved. Cambridge, Harvard University Press.

Hughes, S. M., Dispenza, F., and Gallup, G. G. (2004). Ratings of voice attractiveness predict sexual behaviour and body configuration. Evolution and Human Behavior, 25, 295-304.

Hughes, S. M., Harrison, M. A., and Gallup, G. G. Jr. (2002). The sound of symmetry: voice as a marker of developmental instability. Evolution and Human Behavior, 23, 173-180.

Hughes, S. M., and Rhodes, B. C. (2010). Making age assessments based on voice: the impact of the reproductive viability of the speaker. Special Issue: Journal of Society. Journal of Social, Evolutionary, and Cultural Psychology, 4, 290-304. 
Jasiénska, G., Ziomkiewicz, A., Ellison, P. T., Lipson, S. F., and Thune, I. (2004). Large breast and narrow waist indicate high reproductive potential in women. Proceedings of the Royal Society of London B, 271, 1213-1217.

Johnston, V. S., and Franklin, M. (1993). Is beauty in the eye of the beholder? Ethology and Sociobiology, 14, 183-199.

Johnston, V. S., Hagel, R., Franklin, M., Fink, B., and Grammer, K. (2001). Male facial attractiveness: evidence for hormone-mediated adaptive design. Evolution and Human Behavior, 22, 251-267.

Jolly, A. (1972). The evolution of primate behavior. New York, MacMillian.

Jones, D. (1995). Sexual selection, physical attractiveness and facial neoteny. Current Anthropology, 36, 723-748.

Jones, D., Brace, C. L., Jankowiak, W., Laland, K. N., Musselmann, L. E., Langlois, J. H., et al. (1995). Sexual Selection, physical attractiveness, and facial neoteny: Cross-cultural evidence and implications. Current Anthropology, 36, 723748.

Jones, B. C., Feinberg, D. R., DeBruine, L. M., Little, A. C., and Vukovic, J. (2008). Integrating cues of social interest and voice pitch in men's preferences for women's voices. Biology Letters, 4, 192-194.

Jones, B. C., Feinberg, D. R., DeBruine, L. M., Little, A. C., and Vukovic, J. (2010). A domain-specific opposite-sex bias in human preferences for manipulated voice pitch. Animal Behaviour, 79, 57-62.

Jones, R. E., and Lopez, K. H. (2006). Human Reproductive Biology. $3^{\text {rd }}$ Edition. New York: Academic Press.

Kirchengast, S., and Gartner, M. (2002). Changes in fat distribution (WHR) and body weight across the menstrual cycle. Collegium Antropologicum, 26, 47-57.

Klofstad, C. A., Anderson, R. C., and Peters, S. (2012). Sounds like a winner: voice pitch influences perception of leadership capacity in both men and women. Proceedings of the Royal Society of London B, 279, 2698-2704.

Kuukasjärvi, S., Eriksson, C. J. P., Koskela, E., Nissinen, K., Mappes, T., and Rantala, M. J. (2004). Attractiveness of women body odours along menstrual cycle: The role of oral contraceptives and receiver sex. Behavioral Ecology, 15, 579584. 
Lass, N. J., Justice, L. A., George, B. D., Balswin, L. M., Scherbick, K. A., and Wright, D. L. (1982). Effect of vocal disguise on estimations of speaker's ages. Perceptual and Motor Skills, 45, 1311-1315.

Law-Smith, M. J., Perrett, D. I., Jones, B. C., Cornwell, R. E., Moore, F. R., Feinberg, D. R., et al. (2006). Facial appearance is a cue to oestrogen levels in Women. Proceedings of the Royel Society of London B, 273, 135-140.

Lenchova, P., Roberts, S. C., and Havlicek, J. (2009). Methods of human body odor sampling: The effect of freezing. Chemical Senses, 34, 127-138.

Love, S. A., Pollick, F. A., and Latinus, M. (2011). Cerebral correlates and statistical criteria of cross-modal face and voice integration. Seeing and Perceiving, 24, 351-367.

Manning, J. T., Scutt, D., Whitehouse, G. H., Leinster, S. J., and Walton, J. M. (1996). Asymmetry and the menstrual cycle in women. Ethology and Sociobiology, 17, 129-143.

Marshall, W., and Tanner, J. (1974). Puberty. In J. A. Davis and J. Dobbing (Eds.), Scientific Foundations of Paediatric (pp. 124-151). Philadelphia, W. B. Saunders Co.

Mendes-Laureano, J., Ferriani, R. A., Reis, R. M., Aquiar-Ricz, L. N., Valera, F. C. P., Küpper, D. S., and Romao, G. S. (2006). Comparison of fundamental voice frequency between menopausal woman and woman at menacme. Maturitas, 55, 195-199.

Miller, G., Tybur, J. M. and Jordan, B. D. (2007). Ovulatory cycle effects on tip earnings by lap dancers: economic evidence for human estrus? Evolution and Human Behavior, 28, 375-381.

Mitro, S., Gordon, A. R., Olsson, M. J., and Lundström, J. N. (2012). The smell of age: perception and discrimination of body odors of different ages. PLoS ONE, 7, e38110.

Møller, A. P., and Pomiankowski, A. (1993). Why have birds got multiple sexual ornaments? Behavioral Ecology and Sociobiology, 32, 167-176.

Morabia, A., and Constanza, M. C. (1998). The World Health Organization Collaborative Study of Neoplasia and Steroid Contraceptives: International variability in ages at menarche, first live birth and menopause. American Journal of Epidemiology, 148, 1195-1205. 
Nelson, R. J. (2000). An introduction to behavioural endocrinology, Sunderland: Massachusetts: Sinauer Associates.

O’Connor, J. J. M., Feinberg, D. R., Fraccaro P. J., Borak, D. J., Tigue, C. C., Re, D. E., et al. (2011). Female preferences for male vocal and facial masculinity in videos. Ethology, 118, 321-330.

O'Connor, J. J. M., Fraccaro, P. J., and Feinberg, D. R. (2012). The influence of male voice pitch on women's perceptions of relationship investment. Journal of Evolutionary Psychology, 10, 1-13.

Orlikoff, R. F. (1990). The relationship of age and cardiovascular health to certain acoustic characteristics of male voices. Journal of Speech, Language, and Hearing Research, 33, 450-457.

Pawlowski, B., and Dunbar, R. I. M. (1999). Impact of market value on human mate choice decisions. Proceedings of the Royal Society of London B, 266, 281-285.

Perrett, D. I., Lee, K. J., Penton-Voak, I., Rowland, D., Yoshikawa, S., Burt, D. M., et al. (1998). Effects of sexual dimorphism on facial attractiveness. Nature, 394, 884-887.

Perrett, D. I., May, K. A., and Yoshikawa, S. (1994). Facial shape and judgments of female attractiveness. Nature, 368, 239-242.

Peters, M., Rhodes, G., and Simmons, L. W. (2007). Contributions of the face and body to overall attractiveness. Animal Behavior, 73, 937-942.

Pipitone, R. N., and Gallup, G. G. (2008). Women's voice attractiveness varies across the menstrual cycle. Evolution and Human Behavior, 29, 268-274.

Poran, N. S. (1994). Cyclic attractivity of human female odors. Advances in the Biosciences, 93, 555-560.

Preti, G., and Huggins, G. R. (1975). Cyclical changes in volatile acidic metabolites in human vaginal secretions and their relation to ovulation. Journal of Chemical Ecology, 1, 361-368.

Provost, M. P., Troje, N. F., and Quinsey, V. L. (2008). Short-term mating strategies and attraction to masculinity in point-light walkers. American Journal of Preventive Medicine, 29, 65-69.

Ptacek, P. H., and Sander, E. K. (1966). Age recognition from voice. Journal of Speech and Hearing Research, 9, 273-277. 
Puts, D. A., Bailey, D. H., Cárdenas, R. A., Burriss, R. P., Welling, L. L. M., Wheatley, J. R., et al. (2013). Women's attractiveness changes with estradiol and progesterone across the ovulatory cycle. Hormones and Behavior, 63, 13-19.

Puts, D. A., Barndt, J. L., Welling, L. L. M., Dawood, K., and Burriss, R. P. (2011). Intrasexual competition among women: Vocal femininity affects perceptions of attractiveness and flirtatiousness. Personality and Individual Differences, 50, 111-115.

Puts, D. A., Jones, B. C., and DeBruine, L. M. (2012). Sexual selection on human faces and voices. Journal of Sex Research, 49, 227-243.

Re, D. E., O’Connor, J. J. M., Bennett, P.J., and Feinberg, D. R. (2012). Preferences for very low and very high voice pitch in humans. PLOS ONE, 7, e32719.

Rhodes, G. (2006). Evolutionary psychology of facial beauty. Annual Review of Psychology, 57, 199-226.

Rhodes, G., Simmons, L. W., and Peters, M. (2005). Attractiveness and sexual behaviour: does attractiveness enhance mating success? Evolution and Human Behavior, 26, 186-201.

Rhodes, G., and Zebrowitz, L. A. (2002). Facial attractiveness: evolutionary, cognitive, and social perspectives. Ablex.

Rikowski, A., and Grammer, K. (1999). Human body odour, symmetry, and attractiveness. Proceedings of the Royal Society B, 266, 869-874.

Roberts, S. C., Havlicek, J., Flegr, J., Hruskova, M., Little, A. C., Jones, B .C., Perrett, D.I., and Petrie, M. (2004). Female facial attractiveness increases during the fertile phase of the menstrual cycle. Proceedings of the Royal Society of London B, 271, 270-272.

Roberts, S. C., Kravlevich, A., Ferdenzi, C., Saxton, T. K., Jones, B. C., DeBruine, L. M., et al. (2011). Body odor quality predicts behavioral attractiveness in humans. Archives of Sexual Behavior, 40, 1111-1117.

Röder, S., Fink, B., Feinberg, D. R., and Neave, N. (2013a). Facial visualizations of women's voices suggest a cross-modality preference for femininity. Evolutionary Psychology, 11, 227-237.

Röder, S., Fink, B. and Jones, B. C., (2013b). Facial, olfactory, and vocal cues to female reproductive value. Evolutionary Psychology, 11, 392-404.

Ryan, W. J. (1972). Acoustic aspects of the aging voice. Journal of 
Gerontology, 27, 265-268.

Saxton, T. K., DeBruine, L. M., Jones, B. C., Little, A. C., and Roberts, S. C. (2009). Face and voice attractiveness judgements change during adolescence. Evolution and Human Behavior, 30, 398-408.

Schaefer, K., Fink, B., Grammer, K., Mitteroecker, P., Gunz, P., and Bookstein, F. L. (2006). Female appearance: facial and bodily attractiveness as shape. Psychology Science, 48, 187-204.

Schmitt, D., Timmermans, B., Van Overwalle, F., and Vanhoomissen, T. (2003). Universal sex differences in the desire for sexual variety: tests from 52 nations, 6 continents, and 13 islands. Journal of Personality and Social Psychology, 85, 85-104.

Scutt, D., and Manning, J. T. (1996). Symmetry and ovulation in women. Human Reproduction, 11, 2477-2480.

Shipp, T., and Hollien, H. (1969). Perception of the aging male voice. Journal of Speech and Hearing Research, 12, 703-710.

Singh, D., and Bronstad, P. M. (2001). Female body odour is a potential cue to ovulation. Proceedings of the Royal Society of London B, 268, 797-801.

Singh, D., and Young, R. K. (1995). Body weight, waist-to-hip ratio, breasts, and hips: Role in judgements of female attractiveness and desirability for relationships. Ethology and Sociobiology, 16, 483-507.

Smith, E. L., Grabowecky, M., and Suzuki, S. (2007). Auditory-visual crossmodal integration in perception of face gender. Current Biology, 17, 1680-1685.

Sweeting, P. M., and Baken, R. J. (1982). Voice onset time in a normalaged population. Journal of Speech and Hearing Research, 25, 129-134.

Symons, D. (1979). The Evolution of Human Sexuality. Oxford, UK: Oxford University Press.

Symons, D. (1995). Beauty is in the adaptations of the beholder. In P. R. Abramson and S. D. Pinkerton (Eds.), Sexual Nature, Sexual Culture (pp. 80-118). Chicago: University of Chicago Press.

Tarin, J. J., and Gomez-Piquer, V. (2002). Do women have hidden heat periode? Human Reproduction, 17, 2243-2248.

Thornhill, R., and Gangestad, S. W. (1999). The scent of symmetry: a human sex pheromone that signals fitness? Evolution and Human Behavior, 20, 175- 
201.

Thornhill, R., and Gangestad, S. W. (2008). The evolutionary biology of human female sexuality. Oxford University Press, New York.

Thornhill, R., and Grammer, K. (1999). The body and face of woman: one ornament that signals quality? Evolution and Human Behavior, 20, 105-120.

Titze, I. R. (1994). Principles of voice production. Englewood Cliffs, NJ: Prentice-Hall.

Tovée, M. J., and Cornelissen, P. L. (2001). Female and male perceptions of female physical attractiveness in front-view and profile. British Journal of Psychology, 92, 391-402.

Tovée, M. J., Hancock, P. J., Mahmoodi, S., Singleton, B. R., and Cornelissen, P. L. (2002). Human female attractiveness: waveform analysis of body shape. Proceedings of the Royal Society of London B, 269, 2205-2213.

Trivers, R. L. (1972). Parental investment and sexual selection. In B. Campbell (Ed.), Sexual Selection and the Descent of Man. London, Heinemann.

von Kriegstein, K., and Giraud, A-L. (2006). Implicit multisensory associations influence voice recognition. PloS Biology, 4, e326.

van den Berghe, P. L., and Frost, P. (1986). Skin colour preference, sexual dimorphism and sexual selection: A case of gen-culture co-evolution? Ethnic and Racial Studies, 9, 87-113.

Vukovic, J., Feinberg, D. R., DeBruine, L. M., Smith, F. G., and Jones, B. C. (2010). Women's voice pitch is negatively correlated with health risk factors. Journal of Evolutionary Psychology, 8, 217-225.

Wilcox, A. J., Weinberg, C. R., and Baird, D. D. (1995). Timing of sexual intercourse in relation to ovulation. Effects on the probability of conception, survival of the pregnancy, and sex of the baby. The New England Journal of Medicine, 333, 1517-1521.

Williams, G. C. (1966). Natural selection, the costs of reproduction, and a refinement of Lack's principle. American Naturalist, 100, 687-690.

Williams, G.C. (1975). Sex and evolution. Princeton, Oxford University Press.

Wood, J. W. (1989). Fecundity and natural fertility in humans. Oxford Reviews on Reproductive Biology, 11, 61-109. 
Yovel, G., and Belin, P. (2013). A unified coding strategy for processing faces and voices. Trends in Cognitive Sciences, 17, 263-271.

Zenker, W. (1964). Questions regarding the function of external laryngeal muscles, (pp 20-40). D. W. Brewer (Ed.), Research potentials in voice physiology. Syracuse, NY: State University of New York Press. 


\title{
CURRICULUM VITAE
}

\author{
SUSANNE RÖDER (MSc)
}

Date of birth: 17.02.1981 in Herford, Germany

Nationality: German

Institutional address:

Department of Sociobiology/Anthropology,

Institute of Zoology \& Anthropology,

University of Goettingen

Kellnerweg 6

phone: +49 (0) 551397802

D-37077 Goettingen

email: sroeder@gwdg.de

\section{EDUCATION \& WORK}

Since 2011 PhD student and research assistant

$\mathrm{PhD}$ thesis "Visual, olfactory and vocal cues to female fecundity"

Supervisor: Dr. Bernhard Fink

Department of Sociobiology/Anthropology, Institute of Zoology \& Anthropology, University of Goettingen

2008-2010 Graduate research assistant

Department of Sociobiology/Anthropology, Institute of Zoology \& Anthropology, University of Goettingen

2007-2008 Diploma thesis "Evolutionary psychology of female behaviour across the menstrual cycle"

Supervisor: Dr. Bernhard Fink

Department of Sociobiology/Anthropology, Institute of Zoology \& Anthropology, University of Goettingen

2007 Oral annual examination in Biology, University of Goettingen

Subjects: zoology, botany, microbiology

2001-2007 Basic studies of Biology (Diploma) at the University of Goettingen 
7. Röder, S., Fink, B., \& Jones, B. C. (2013). Facial, olfactory, and vocal cues to female reproductive value. Evolutionary psychology, 11, 392-404.

6. Röder, S., Fink, B., Feinberg, D. R., \& Neave, N. (2013). Facial visualizations of women's voices suggest a cross-modality preference for femininity. Evolutionary Psychology, 11, 227-237.

5. Fink, B., Neuser, F., Deloux, G., Röder, S., \& Matts, J. P. (2013). Visual attention to and perception of undamaged and damaged versions of natural and colored female hair. Journal of Cosmetic Dermatology. 12, 78-94.

4. Fink, B., Matts, P.J., D’Emiliano, D., Bunse, L., Weege, B., \& Röder, S. (2012). Colour homogeneity and visual perception of age, health and attractiveness of male facial skin. Journal of the European Academy of Dermatology and Venereology, 26, 1486-92.

3. Fink, B., Weege, B., Flügge, J., Röder, S., Neave, N., \& McCarty, K. (2012). Men's personality and women's perception of their dance quality. Personality and Individual Differences, 52, 232-235.

2. Fink, B., Matts, P. J., Röder, S., Johnston, R., \& Burquest, M. (2011). Differences in visual perception of age and attractiveness of female facial and body skin. International Journal of Cosmetic Science, 33, 126-133.

1. Röder, S., Brewer, G., \& Fink, B. (2009). Menstrual cycle shifts in women's selfperception and motivation: A daily report method. Personality and Individual Differences, 47, 616-619.

\section{PRESENTATIONS}

Röder, S.*, Fink, B., \& Jones, B. C. (2013). Facial, olfactory and vocal cues to female reproductive potential. $25^{\text {th }}$ Annual Conference of the Human Behavior and Evolution Society (HBES), July17-20, Miami Beach, Florida, USA. (Talk)

Röder, S.*, Habenicht, C., \& Fink, B. (2013). Women's faces and voices: one ornament of quality? $25^{\text {th }}$ Annual Conference of the Human Behavior and Evolution Society (HBES), July 17-20, Miami Beach, Florida, USA. (Poster)

Pisanski, K.*, Fraccaro, P., Tigue, C., O’Connor, J., Röder, S., DeBruine, Lisa, Jones, B. C., Fink, B., Andrews, P., \& Feinberg, D. R. (2013). A meta-analysis of voice and body size relationships. $25^{\text {th }}$ Annual Conference of the Human Behavior and Evolution Society (HBES), July 17-20, Miami Beach, Florida, USA. (Talk) 
Fink, B.*, Neuser, F., Deloux, G., Röder, S. \& Matts, P. J. (2013). Visual attention to and perception of female hair condition. $25^{\text {th }}$ Annual Conference of the Human Behavior and Evolution Society (HBES), July 17-20, Miami Beach, Florida, USA. (Poster)

Fink, B.*, Neuser, F., Deloux, G., Röder, S. \& Matts, P. J. (2013). Visual attention to and perception of undamaged and damaged versions of natural and coloured female hair. $7^{\text {th }}$ World Congress of Hair Research, May 4-6, Edinburgh, UK. (Talk)

Röder, S.*, Fink, B., Feinberg, D. R., \& Neave, N. (2012). Facial visualizations of women's voices suggest a cross-modality preference for femininity. $24^{\text {rd }}$ Annual Conference of the Human Behavior and Evolution Society (HBES), June 13-17, Albuquerque, New Mexico. (Talk)

Röder, S.*, Fink, B., Matts, P. J., Johnston, R., \& Burquest, M. (2011). Differences in visual perception of age and attractiveness of female facial and body skin. $23^{\text {rd }}$ Annual Conference of the Human Behavior and Evolution Society (HBES), June 29July 3, Montpellier, France. (Poster)

Weege, B.*, Fink, B., Flügge, J., Röder, S., Neave, N., \& McCarty, K. (2011). Men's personality and women's perception of their dance quality. $23^{\text {rd }}$ Annual Conference of the Human Behavior and Evolution Society (HBES), June 29 - July 3, Montpellier, France. (Poster)

Fink, B.*, Matts, P. J., Röder, S., Johnston, R., \& Burquest, M. (2011). Differences in visual perception of age and attractiveness of female facial and body skin. $22^{\text {nd }}$ World Congress of Dermatology, May 24-29, Seoul, Korea. (e-Poster)

Röder, S. ${ }^{*}$, Brewer, G., \& Fink, B. (2009). Menstrual cycle shifts in women's selfperception and motivation: A daily report method. 10. Tagung der MVE-Liste, March 26-28, Göttingen, Germany. (Poster)

MEDIA

DFG Science TV, Love à la Darwin, 2009.

FUNDING

German Academic Exchange Service (DAAD)

- Student travel allowance for visiting the $25^{\text {th }}$ Annual Conference of the Human Behavior and Evolution Society in Miami Beach, Florida, USA, 2013: 1041 Euro 
Universitätsbund Göttingen e.V.

- Student travel allowance for visiting the $25^{\text {th }}$ Annual Conference of the Human Behavior and Evolution Society in Miami Beach, Florida, USA, 2013: 250 Euro

- Student travel allowance for visiting the $24^{\text {rd }}$ Annual Conference of the Human Behavior and Evolution Society in Albuquerque, New Mexico, USA, 2012: 150 Euro

- Student travel allowance for visiting the $23^{\text {rd }}$ Annual Conference of the Human Behavior and Evolution Society in Montpellier, France,

2011: 200 Euro

Human Behavior and Evolution Society (HBES)

- Funding of student registration costs for the $25^{\text {th }}$ Annual Conference of the Human Behavior and Evolution Society in Miami Beach, Florida, USA, 2013: 150 Euro

- Student travel allowance for visiting the $23^{\text {rd }}$ Annual Conference of the Human Behavior and Evolution Society in Montpellier, France, 2011: 200 Euro

\section{PROFESSIONAL MEMBERSHIPS}

- Universitätsbund Göttingen e.V.

- Human Behavior and Evolution Society (HBES) 


\section{ERKLÄRUNG ÜBER EIGENE LEISTUNG}

Ich versichere, dass ich die vorliegende Arbeit mit dem Titel „Visual, Olfactory, and Vocal Cues to Fecundity in Human Females " selbständig verfasst und keine anderen als die angegebenen Hilfsmittel verwendet habe. Die Stellen, die aus anderen Werken wörtlich oder sinngemäß entnommen sind, sind als solche kenntlich gemacht. Ich versichere weiterhin, dass diese Arbeit in gleicher oder ähnlicher Form noch keiner anderen Prüfungsbehörde vorgelegen hat.

Eigene Beiträge im Verhältnis zu Koautoren bei bereits publizierten oder zur Publikation einzureichenden Teilen dieser Arbeit sind wie folgt:

\section{Kapitel II}

Dr. Bernhard Fink und Susanne Röder verfassten das Design der Studie. Susanne Röder erstellte die Experimente, führte die Datenaufnahmen und Datenanalyse durch und verfasste das Manuskript. Anette Mertens und Corinna Habenicht unterstützten Susanne Röder bei der Rekrutierung der Probanden für die Beurteilungsstudien. Dr. Bernhard Fink und Prof. Dr. Benedict C. Jones wirkten als Coautoren an der Finalisierung des Manuskriptes mit.

\section{Kapitel III}

Dr. Bernhard Fink und Susanne Röder verfassten das Design der Studie. Susanne Röder erstellte die Experimente, führte die Datenaufnahmen und Datenanalyse durch und verfasste das Manuskript. Anette Mertens unterstützte Susanne Röder bei der Rekrutierung der Probandinnen und Probanden für die Beurteilungsstudien. Dr. Bernhard Fink, Prof. Dr. David R. Feinberg und Dr. Nick Neave wirkten als Coautoren an der Finalisierung des Manuskriptes mit.

\section{Kapitel IV}

Dr. Bernhard Fink und Susanne Röder verfassten das Design der Studie. Susanne Röder und Corinna Habenicht erstellten das Experiment und führten die Datenaufnahme und Datenanalyse durch. Susanne Röder verfasste das Manuskript. Dr. Bernhard Fink wirkte als Coautor an der Finalisierung des Manuskriptes mit.

Göttingen, den 24. September 2013

Susanne Röder 


\section{ACKNOWLEDGEMENT}

Special thanks go to my supervisor Dr. Bernhard Fink. Thank you Bernhard, for all your input, help, and your unwavering patience at any time. With your excellent supervision you have contributed significantly to my scientific education and to the development of my $\mathrm{PhD}$ thesis.

Furthermore, I want to thank my Co-authors on the two published articles - David, Nick, and Ben - for your cooperation and for your helpful comments and suggestions.

Thank you all the volunteers who participated in the experiments and also to my "busy bees" for their helping hands with participants recruitments and data collections. I also want to thank the members of my thesis committee and the DFG for funding my PhD project (FI 1450/6-1).

Thank you, my dear colleagues of the Emmy-Noether-Research Group "Evolutionary Psychology" and my dear friends. Without you pursuing a $\mathrm{PhD}$ wouldn't have been that much fun.

My heartfelt gratitude goes to my family for always being supportive of me and for being understanding and proud even about me pursuing my goals in academia. 